Portland State University

PDXScholar

$12-14-1978$

\title{
A Comparison of the Articulatory Proficiency Between Stutterers and Nonstutterers While in a State of Oral Sensory Deprivation
}

Clifford Saul Goldman

Portland State University

Follow this and additional works at: https://pdxscholar.library.pdx.edu/open_access_etds

Part of the Speech Pathology and Audiology Commons Let us know how access to this document benefits you.

Recommended Citation

Goldman, Clifford Saul, "A Comparison of the Articulatory Proficiency Between Stutterers and Nonstutterers While in a State of Oral Sensory Deprivation" (1978). Dissertations and Theses. Paper 2889. https://doi.org/10.15760/etd.2884

This Thesis is brought to you for free and open access. It has been accepted for inclusion in Dissertations and Theses by an authorized administrator of PDXScholar. Please contact us if we can make this document more accessible: pdxscholar@pdx.edu. 
AN ABSTRACT OF THE THESIS OF Clifford Saul Goldman for the Master of Science in Speech Communication, with an emphasis in Speech Pathology/ Audiology, presented December 14, 1978 .

Title: A Comparison of the Articulatory Proficiency Between Stutterers and Nonstutterers While in a State of Oral Sensory Deprivation.

APPROVED BY MEMBERS OF THE THESIS COMMITTEE:

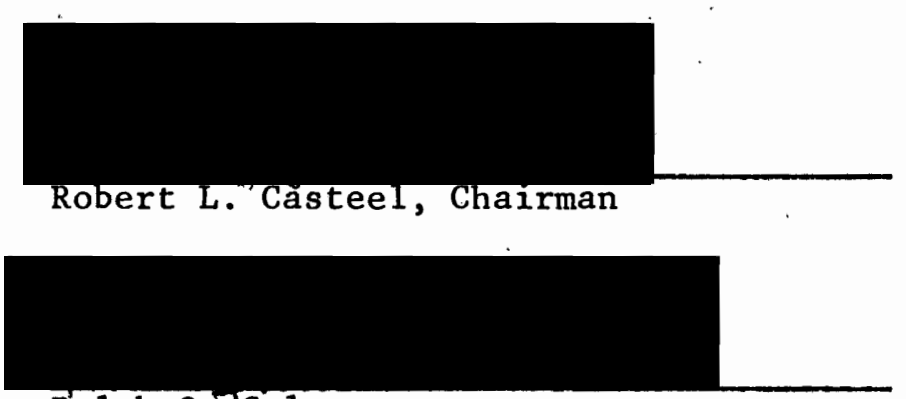

Ra1ph 0.VColeman

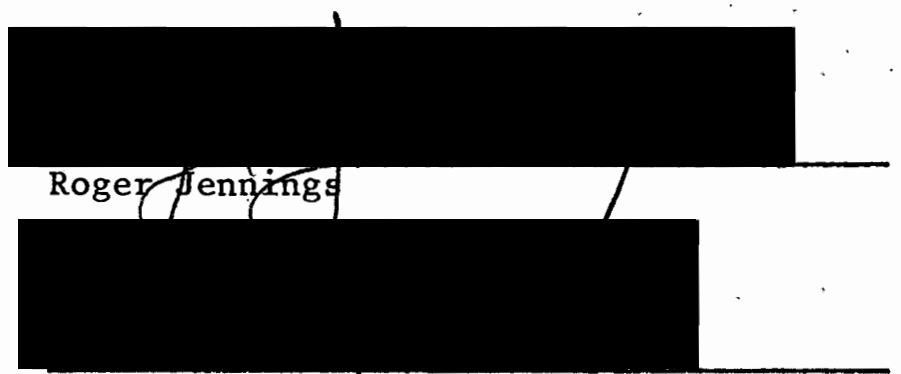

Robert C. Marsha11

The purpose of this thesis was to determine if stutterers monitor speech production differently than nonstutterers while in a state of oral sensory deprivation. The specific questions asked were:

1. Does an imposed oral somesthetic feedback deficit hinder articulation proficiency more in a nonstuttering sample than in a stuttering sample? 
2. If the articulation proficiency is deficient in both samples, does the nature of the errors differ between the two samples?

The answers to these questions were:

1. Articulatory proficiency of nonstutterers was not more impaired than stutterers.

2. The nature of the errors did not significantly differ for either of the samples.

The comparison of the monitoring abilities of speech in stutterers and nonstutterers has become relevant in investigating the nature of stuttering. Researchers (Gruber, 1965, 1970; Webster and Lubker, 1968; Goldiamond, 1965; Mysak, 1960, 1976; Trotter, 1967) have established that stuttering behavior can be reduced with masking and/or DAF. Gruber (1965) and Mysak (1976) have offered as one of the possible explanations for this effect to be a "forced" shift in the monitoring of speech from a possibly faulty auditory feedback channel to a more efficient tactile-proprioceptive sensor. In light of the fluency effect of auditory feedback manipulation with stutterers, explained in terms of a "forced" monitoring shift to the tactile-kinesthetic-proprioceptive sensory systems, and the idea that normally developing children spontaneously shift away from auditory monitoring to the oral sensory systems, Gruber (1965) suggested stutterers may not have made this shift. This writer hypothesized that the present investigation of nonstutterers' articulation would be less proficient than the stutterers' since the nonstutterers could no longer be relying upon oral sensory feedback in a state of oral sensory deprivation. Further, the stutterers' articulation proficiency would be expected to be less affected by the anesthetization if they are depending less upon the tactilekinesthetic-proprioceptive feedback and more upon auditory sensory 
feedback. The relationship between articulatory proficiency and induced oral sensory deprivation states has been researched and also was reviewed.

Oral anesthetization procedures, in this study, consisted of the administration of bilateral mandibular nerve block injections by two dentists, upon six male stutterers and six nonstutterers.

Three licensed speech and language pathologists serving as judges listened separately to each tape. Judgments made were (1) right/wrong and (2) identification of error (distortion, omission, substitution, addition). Through the use of a $t$ test, the results showed no significant difference in articulatory proficiency between the stutterer and nonstutterer at the .05 leve1 $(p>.05)$ of confidence. Neither was there a significant difference between samples for the types of errors committed.

These results suggested that both stutterers and nonstutterers monitor speech the same way. The expectation that the nonstutterers' articulation would be less proficient was not demonstrated; hence, from this study it cannot be said that stutterers monitor their speech less orally than nonstutterers. Another interpretation was offered, however:

The observation that there was no significant difference in articulatory proficiency between the two samples while in the state of oral sensory deprivation does not necessarily lead to the discarding of the idea that stutterers and nonstutterers monitor speech differently. It was discussed that the difference could possibly lie in the proprioceptive system (or component) of oral sensory feedback, as it was realized after completing the study that anesthetization of the 
articulators eliminates tactile, but not necessarily proprioceptive feedback (Gammon et a1., 1972; Mysak, 1976).

Therefore, it may be said that loss of tactile feedback for both nonstutterers and stutterers results in minor articulation errors while in an oral sensory deprived state. One may still wonder if the difference in speech monitoring (if any) between stutterers and nonstutterers is in the proprioceptive system of oral feedback rather than in the presumed tactile feedback system. 


\section{A COMPARISON OF THE ARTICULATORY PROFICIENCY BETWEEN STUTTERERS AND NONSTUTTERERS WHILE IN A STATE OF ORAL SENSORY DEPRIVATION}

$$
\text { by }
$$

CLIFFORD SAUL GOLDMAN
A thesis submitted in partial fulfillment of the requirements for the degree of

\section{MASTER OF SCIENCE IN SPEECH COMMUNICATION: with an emphasis in SPEECH PATHOLOGY/AUDIOLOGY}


TO THE OFFICE OF GRADUATE STUDIES AND RESEARCH:

The members of the Committee approve the thesis of Clifford Saul Goldman presented December 14, 1978 .

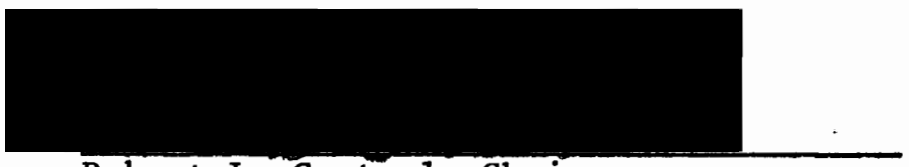

Robert L. Castee1, Chairman

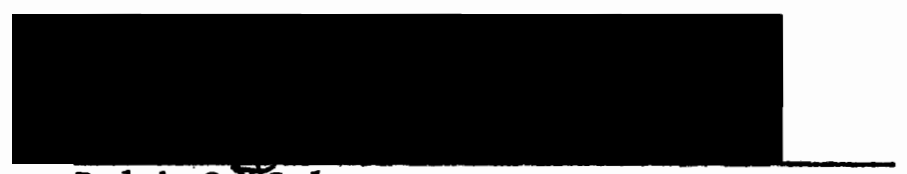

Ralph 0. Coleman

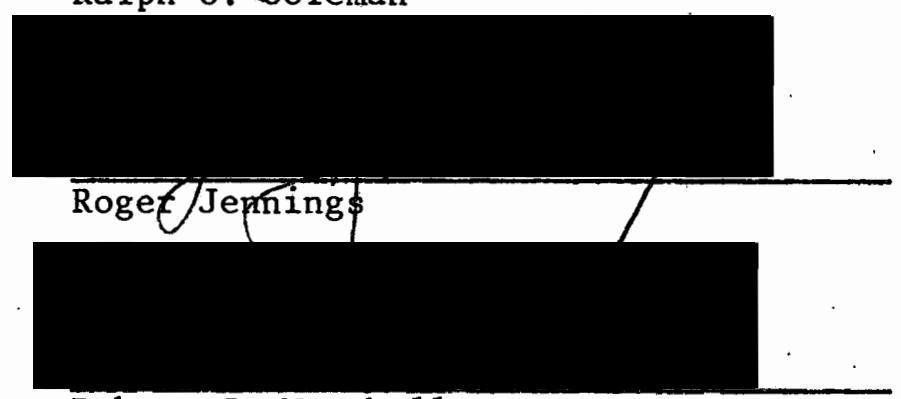

Robert C. Marsha11

APPROVED :

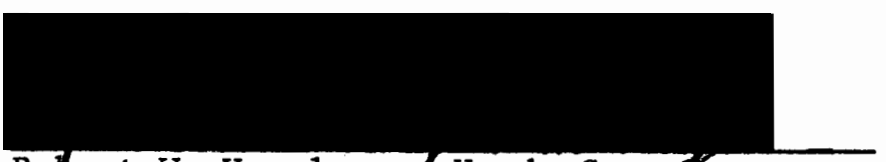

Rolert W. Vogelsang/ Head, Speeg
Communicatiof Department

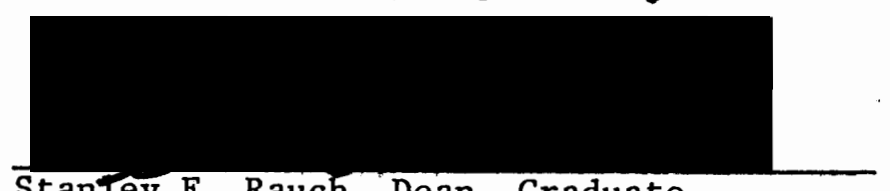

Staniey E. Rauch, Dean; Graduate

Studies and Research 


\section{ACKNOWLEDGMENTS}

The fact that I am a stutterer and have chosen to become a speech pathologist is not particularly unique in this field. Several pioneers in the young field of speech pathology were stutterers. Mentioning this helps me in attempting to acknowledge the fullness of gratitude I feel toward certain individuals who have helped me to manage my own stuttering, as well as have contributed toward my scholastic growth, specifically, this document. Also, I must acknowledge my own enduring qualities. Without the tenacity which I displayed at times when there seemed not much reason for going on, I could not have demonstrated to myself that I am capable of joining those in the tradition who contribute to knowledge.

Special thanks must go to Dr. Robert L. Casteel, who showed me that I could indeed be fluent and without whom I may not have been able to choose to work in the field of clinical speech. His efforts in piloting me through the labyrinth of the thesis process are greatly appreciated.

Appreciation also must be expressed to Dr. Ronald L. Webster of the Hollins Communication Research Institute, Hollins College, Roanoke, Virginia, who opened up another vista for me in my understanding of stuttering and its treatment. This thesis is a product of the professional excitement he stimulated within me.

Thanks also go to Dr. Robert C. Marsha11, who at those confusing times provided me with the organizational clarity I needed to know how 
to do the project. As a committee member, and especially as a friend, he enabled me to generate the inner strength necessary to go on. Dr. Jack Hegrenes did my statistical work and provided the encouragement for me to see beyond any problem being experienced. His support and fairness were paramount toward my completing the thesis.

I also wish to thank Dr. Ralph 0 . Coleman for his guidance regarding experiments dealing with oral anesthetization procedures. It was comforting to me to have on my committee one who has published in this area. Appreciation also goes to Dr. Roger Jennings of the Portland State psychology department, who generously gave his time to participate on the committee.

Dr. James Bennett, professor of dentistry at the University of Oregon Dental School, receives my thanks for helping me examine the risks and safeguards regarding anesthetization of the subjects。 I cannot say enough about the contribution given by Drs. Alan Clarke and Frank McKeown, dentists. Dr. Clarke donated over twenty hours and Dr. Mckeown one evening in administering the injections to the subjects. Without them, this thesis may not even have gone beyond Chapter III. Finally, thanks go to my wife, Nancy, for her patience and understanding during the many long hours the thesis took me away from the family, and to my mother and father, Clare and Jerry Goldman, who always have provided the environment and encouragement for my selfdevelopment. 
TABLE OF CONTENTS

PAGE

ACKNOWLEDGMENTS . . . . . . . . . . . . . . . . . . .

LIST OF TABLES . . . . . . . . . . . . . . . . . . . . . viii

CHAPTER

I BACKGROUND AND INTRODUCTION . . . . . . . . . . . 1

Statement of Purpose . . . . . . . . . . 3

Definition of Terms . . . . . . . . . . . 3

II REVIEW OF THE LITERATURE . . . . . . . . . . . . . 5

Articulatory Proficiency and Sensory Deprivation 5

Speech During Auditory, Oral Sensory

Deprivation

Speech During Oral Sensory Deprivation

Speech Studied Under Combinations of Auditory and Sensory Deprivation

Role of Kinesthesia and/or Proprioception

During Tactile Deprivation

Coleman and Schliesser (1972) Disagree

Regarding Role of Kinesthesia

Intelligibility Maintenance Related to

Proprioception

Closed-Loop and Open-Loop Considerations

Stuttering and Sensory Feedback . . . . . . .

Stuttering as Deautomatization

Discoordination of Phonation with

Respiration and Articulation

Delay of Stutterers' Voice Initiation

Response Time

Webster's Auditory Interference Theory:

Possible Middle-Ear Involvement

Stuttering Viewed as Central Auditory

Dysfunction

Closed-Open-Loop Paradigm 


\section{Articulation Proficiency of Stutterers}

Versus Nonstutterers

III

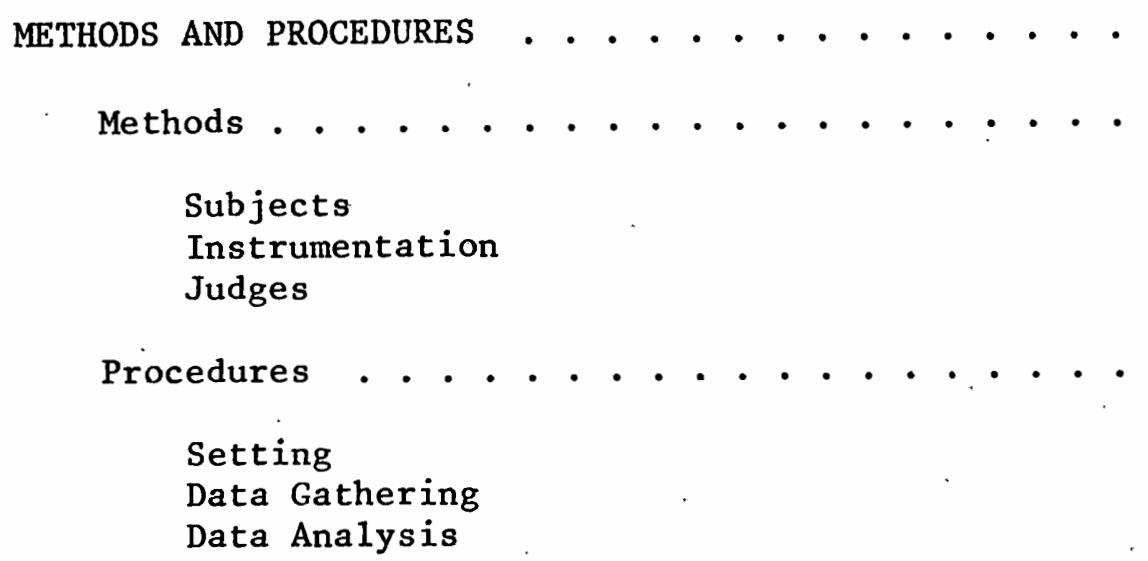

Subjects

Instrumentation

Judges

Procedures . . . . . . . . . . . . .

Setting

Data Gathering

Data Analysis

IV RESULTS AND DISCUSSION • • • • • • • • • • • • •

Results . . ... . . . . . . . . . .

Discussion . . . . . . . . . . . . .

V SUMMARY AND IMPLICATIONS

Summary • • • • • • • • • • • • • • • • •

Implications . . . . . . . . . . . . • .

C1inica1

Coordination for Initiation of Speech and Feedback Considerations Middle-Ear Muscle Component of Fluent Speech Research

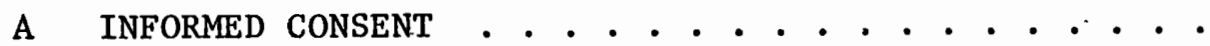

B DENTIST AUTHORIZATION . • • • • • . • • • • • . •

C INSTRUCTIONS TO JUDGES . . . . . . . . . . . . .

D JUDGES' RESPONSE SHEET • . . . . . . . . . . . . .

E ANESTHETIZATION CRITERIA SCORING SHEET . . . . . . 
F SUMMARY OF JUDGES' SCORING CORRECT AND MISARTICULATED RESPONSES OF BOTH SAMPLES 


\section{LIST OF TABLES}

I Mean Scores, Standard Deviations, and Value of $t$ at .05 Leve1 of Significance for Number of Incorrectly Articulated Words As Produced by Stutterers and Nonstutterers During Induced Oral Sensory Deprivation . . . . . . . . . . . . .

II Percentage Comparison of Type of Errors Produced Between Stutterers and Nonstutterers During Oral Sensory Deprivation; and Mean Scores and Standard Deviations . . . . . . . . . . . . .

III Values of $t$ Relative to Type of Articulatory Error Between Stutterers and Nonstutterers During Oral Sensory Deprivation . . . . . . . . . . . .

IV Judge Inter-Reliability: A11 Three in 100 Per Cent Agreement . . . . . . . . . . . . . . . . 


\section{CHAPTER I}

\section{BACKGROUND AND INTRODUCTION}

Stuttering has been studied from several different theoretical perspectives. These include disintegration theories (Travis, 1931; West, 1936), anticipation theories (Johnson, 1955; Van Riper, 1954), psychoanalytically derived theories (Coriat, 1928; Barbara, 1958), learning theories (Wischner, 1950; Sheehan, 1958; Shames and Sherrick, 1963), and, finally, servosystem paradigms (Fairbanks, 1954; Mysak, 1960, 1976; Webster and Lubker, 1968), which account for the occurrence of stuttering as disruptions that occur in the flow of speech when feedback loops are disturbed. Webster and Lubker (1968) held that the delayed contraction of the middle-ear muscles in association with the initiation of phonation could be responsible for producing disruption in the properties of auditory feedback signals used in speech guidance. Gruber (1965) stated that sensory reception may cause disruption of speech flow. He contended that the auditory channel is the prime monitoring agent for the child's early speech development, but that this is ultimately replaced by the kinesthetic or tactual feedback channels with auditory feedback remaining active but assuming a secondary role. Gruber (1965) suggested that the stutterer's speech development "has become arrested at the auditory level of speech monitoring and has failed to make the transition to the tactual and proprioceptive avenues." Proponents of this theory state that the use of the voice 
masker in stuttering therapy shifts the stutterer's monitoring set from the auditory to the proprioceptive, tactile, and kinesthetic channels so as to increase speech fluency. Hutchinson (1973) anesthetized stutterers and found they exhibited more stuttering while in a state of profound oral sensory deprivation. He suggested that stuttering increased because the stutterers no longer were able to mitigate their stuttering through oral sensory feedback (closed-loop) regulation. Nonstutterers do not stutter while in a state of oral sensory deprivation, but other effects upon otherwise normal speech production may conveniently be studied.

Speech researchers have investigated the role which oral sensory receptors play in the articulatory proficiency of speech production in normal speakers by means of inducing oral sensory deprivation. Under conditions of oral anesthetization, speech has been analyzed via phonemic (McCroskey, 1958; Ringel and Steer, 1963; Schliesser and Coleman, 1968; Gammon et a1., 1971), phonetic-spectrographic (Scott and Ringel, 1971), photographic (Putnam and Ringel, 1972), acoustic (Horii et al., 1973) and cineradiographic methodologies (Putnam and Ringe1, 1976). The studies have shown that normal subjects' speech under states of induced oral sensory deprivation is characterized by minor articulatory deficiencies, primarily nonphonemic in nature, but does not suffer a diminution in overal1 intelligibility. The articulation of stutterers has not been tested under these conditions. As noted, Hutchinson (1973) did anesthetize stutterers, but not with a control group and not to compare articulation proficiency between stutterers and nonstutterers. Still to be explored is the possibility that differences exist in 
the articulatory monitoring servosystems of stutterers and nonstutterers and that these differences may partially account for stuttering.

\section{Statement of Purpose}

The purpose of this thesis is to determine if stutterers monitor speech production differently than nonstutterers while in a state of oral sensory deprivation. The specific questions to be answered are:

1. Does an imposed oral somesthetic feedback deficit hinder articulation proficiency more in a nonstuttering sample than in a stuttering sample?

2. If the articulation proficiency is deficient in both samples, does the nature of the errors differ between the two samples?

\section{Definition of Terms}

Open-1oop feedback. Autonomous generation of neuromotor impulses from the central nervous system to articulators without reference to peripheral sensory feedback from the oral cavity (Putnam and Ringel, 1972).

On-off. Refers to open-1oop feedback (Liberman et a1., 1967). Closed-loop feedback. Speech system constantly adjusting its neuromotor output on the basis of peripheral feedback information; all driving signals received by the articulatory structures are signals that have been processed, or altered in accordance with information from peripheral receptors (Fairbanks, 1954).

Go-to. The articulatory movement pattern resulting from closedloop guidance (Liberman et a1., 1967).

Secondary stutterers. These persons exhibit and experience 
phoneme, word, situation fears and anticipatory avoidance with the embarrassment of stuttering (Hutchinson, 1973).

Kinesthesia. The muscle sense; the sense of perception of movement, weight, resistance, and position (Blakiston's New Gould Medical Dictionary, 1956).

Proprioception. Appreciation of position, balance, and changes in equilibrium on the part of the muscular system, especially during locomotion (Blakiston's New Gould Medical Dictionary, 1956).

Tactile. Pertaining to the sense of touch (Blakiston's New Gould Medical Dictionary, 1956$)$.

Servosystem. A system that employs feedback of the output to the place of control, comparison of the output to the input, and such manipulation of the out-producing device as will cause the output to have the same functional form as the input (Fairbanks, 1954).

Stereognosis. The ability to recognize the form of objects through the sense of touch (Ringel et al., 1968). 
CHAPTER II

REVIEW OF THE LITERATURE

The review of the literature will consider two areas of research; it will, therefore, be divided into two sections. The first section will review research regarding articulatory proficiency during sensory deprivation. The second section will focus on stuttering and sensory feedback.

\section{Articulatory Proficiency and Sensory Deprivation}

Speech During Auditory, Ora1 Sensory Deprivation

Speech has been analyzed under conditions of oral sensory deprivation to determine what effect this condition may have upon articulatory performance. McCroskey (1958) hypothesized that if the major monitoring influence of speech production is auditory, then disruption of sensory cues stemming from the lips and oral cavity should not seriously impair speech efficiency. The speech task was a word list read by the subject. The two independent variables were (1) delayed auditory sidetone and (2) oral sensory deprivation. McCroskey found there was no significant difference in articulatory performance between normal and delayed sidetone, but there was a statistically significant reduction in the number of words correctly spoken in the oral sensory deprived state. McCroskey concluded from this that auditory feedback is a major factor in determining the rate of speech, and tactile 
feedback seems to be of greater importance to accuracy.

Speech During Oral Sensory Deprivation

Ringel and Steer (1963) conducted a study of the articulatory proficiency of talkers under oral sensory deprivation. They noted significant alterations in articulatory performance, as well as extended mean syllable durations.

Speech Studied Under Combinations of Auditory and Sensory Deprivation

Sch1iesser and Coleman (1968) studied the effects of four different conditions upon speech: (1) auditory masking and oral anesthesia, (2) oral anesthesia alone, (3) auditory masking alone, and (4) normal. They concluded that tactile sensation can be eliminated from the oral cavity without significantly affecting motor innervation, and that without tactile and auditory feedback speech can be produced that is intelligible while exhibiting a "moderate" degree of defectiveness. They hypothesized talkers may use well-learned motor patterns with such a high degree of accuracy that no sensory feedback is required for short term monitoring. Kozhevnikov and Chistovich (1966) have stated that once an articulatory unit becomes programmed through learning, it may become relatively self-perpetuating. This implies that a programmed articulatory unit would be to some extent independent of any feedback system.

Role of Kinesthesia and/or Proprioception During Tactile Deprivation

Gammon, Smith, Daniloff and Kim (1971) studied articulatory behavior in detail and attempted to determine whether a learned unit of 
articulation, if it becomes self-perpetuating, would to an extent be independent of any feedback system. They found that articulatory proficiency, as. in the Schliesser and Coleman study (1968), was affected the most from tactile deprivation, whereas auditory deprivation affected consonant production only slightly. When talkers were subjected to massive feedback disruption, more than 80 per cent of a11 consonants were correctly articulated, supporting the contention that the articulatory system is relatively independent of feedback systems. Gammon et al. (1971) believe kinesthesia not to be significantly affected by anesthesia and thereby contributed information which enabled sufficiently accurate tongue placement for proper phonemic quality. Tactile feedback is needed for good phonetic quality; and it was the phonetic, not the phonemic, quality which was faulty. In other words, Gammon et al. (1971) suggested that speech produced under the influence of oral sensory deprivation remains intelligible because of a significant degree of phonemic invariability due to intact kinesthesia. They summarize their findings by saying that due to elimination of the tactile feedback, consonantal variability is significant, thus producing articulatory errors which from this analysis can be said to be phonetic in nature, not phonemic; tactile in nature, not kinesthetic; articulatorily inadequate in nature, not unintelligible (Gammon et al., 1971).

Coleman and Schliesser (1972) Disagree Regarding Role of Kinesthesia

Coleman and Schiliesser (1972) disagreed with the conclusion of Gammon et a1. (1971) that intact kinesthesia is responsible for speech 
intelligibility despite the fact that both studies used similar anesthetization procedures and both found speech to be reasonably well produced. The difference in conclusions between the researchers seems to be the role assigned to kinesthesis in the tongue in maintaining articulatory accuracy. Schliesser and Coleman (1968) contend that kinesthesia was eliminated from the tongue. The test to verify absence of kinesthesia was the manipulation of the subject's tongue with forceps. With eyes closed, the subject was to identify the type of movement and static tongue position. The results were that manipulations of the tongue could not be detected by the subject, indicating the elimination of kinesthesia.

Intelligibility Maintenance Related to Proprioception

Coleman and Schliesser explain the lack of phonemic changes in the condition of oral sensory deprivation by citing Kozhevnikov and Chistovich (1966), who hypothesized the articulatory unit once learned becomes self-perpetuating, thus independent of any feedback system. Gammon et a1. (1972) in a letter responded to Coleman and Schliesser (1972) by saying the mechanical manipulation of a passive tongue is not identical to tongue movements initiated by the talker's own muscles in terms of resulting proprioception; therefore, such a test does not rule out the presence of kinesthesia in the tongue. It should be noted, however, Gammon et a1. (1972) did appear to modify their point of view in that they admit their use of the term "kinesthesis" to describe position sense for the tongue during anesthesia". . may not be warranted since kinesthesia is, as Schliesser and Coleman say, reserved for sensation evoked from sensory receptors located in ligaments and 
tendons at the points." But Gammon et a1. (1972) in their answer to Coleman and Schliesser's letter (1972) did maintain that until the extent and import of neuromuscular spindle feedback is determined and until there is further evidence concerning the effect of anesthesia upon such pathways, proprioceptive sensation in the maintenance of articulation control cannot be ruled out. So it seems that Coleman and Schliesser's (1972) comment on Gammon et a1. (1971) influenced the 1atter to be less ready to use the term "kinesthesia" in their explanation of how speech intelligibility is maintained under anesthesia, but not for Coleman and Sch1iesser's (1972) reason (manipulation of the tongue with forceps), but rather in the use of a more accurate term to describe the reason for the phenomenon of maintained speech intelligibility under the condition of oral sensory deprivation, proprioception.

\section{Closed-Loop and Open-Loop Considerations}

Spectographic Analysis. Scott and Ringel (1971) in detail analyzed the articulatory changes of twenty-four bisyllabic words using side band spectograms. As in other studies noted above, they found the articulatory errors to be nonphonemic and to have included a loss of retroflection and liprounding gestures, less close fricative constrictions and retracted place of articulation. In short, a closed-loop counterpart was present for some articulatory events but not for others. The stops were characterized by (1) retracted (more posterior than usual) place of closure for /tdkg/. For example, the velar stops $/ \mathrm{kg} /$ were produced as uvular stops /qG/, and the /td/ were produced in the prepalatal or palatal area; (2) upper lip inactivity for /pb/; and (3) affricated release of voiceless initial stops. Scott and Ringel 
Ringe1 (1971) did not observe the tendency for the fricatives to become stops as did Gammon et a1. (1971); rather, they retained their fricative manner of production. They were, however, less close (contact space between articulators) and exhibited a retracted manner of constriction. Apical retroflexion for $/ x /$ was occasionally. lost or reduced and $/ w /$ was characterized by delabialization, a lip configuration less close and less protruded. Nasal consonants were not affected by nerve block anesthesia. Viewing articulatory behavior as a feedback system, Scott and Ringel (1971) stated that neither open- nor closedloop systems alone accounted for oral sensory feedback in articulation production. Nerve block anesthesia does result in articulation errors but not as severe as they should suspect if articulation were governed exclusively by closed-1oop feedback. If speech control were entirely open-1oop in nature, speech being controlled autonomous1y in the absence of peripheral oral sensory feedback, no articulatory changes during a condition of oral sensory deprivation would be expected. Scott and Ringel (1971) cite MacNeilage's (1970) statement that the open-loop control mechanism". . would not have to wait for information associated with actually reaching the previous location in order to control the following movement appropriately." An acceptance of open-loop as controlling speech, however, may not be feasible. Scott and Ringel (1971) cite MacNeilage (1970) to state that the acceptance of an open-loop system would require the prestoring and ready recall of up to as many as 100,000 unique allophonic motor patterns. They say although this is a possibility, investigators have been bothered intuitively by the apparent inefficiency of a system operating that way. 
Several investigators, in the attempt to accommodate such considerations, have been led to hypothesize open- and closed-loop government of speech and to search for examples to support one or the other, say Scott and Ringe1 (1971). They cite MacNeilage, Krones, and Hanson (1970) as having reported on jaw movement and the interpretation for closed-loop control in the initiation of speech. Summarizing this, MacNeilage (1970), as stated in Scott and Ringel (1971), observed the jaw position adopted for a given initial segment shows variation of only 1 to 2 millimeters with repetitions of the same utterance. For this to happen the production mechanism must account for the pre-speech position of the jaw, and make a speech-initial jaw movement contingent upon the pre-speech position. Scott and Ringel (1971) cite Ohman's work (1965) as supporting closed-loop control in ongoing speech. They say Ohman used spectographic analysis to find that vowe1-consonant and consonant-vowel formant transitions are nearly identical, in producing the stop /d/ within different articulatory contexts. Further evidence of closed-loop control is found in Kozhevnikov and Chistovich (1966). Scott and Ringe1 (1971) found that the velocity of the lower closure in bilabial consonants is directly proportional to the amount of 1 ip opening for the preceding vowel.

Scott and Ringel (1971) stated that while many of these investigations of open- and closed-loop control systems were concerned with the problem of motor equivalence in speech production, or how the articulators achieve a relatively constant target from a variety of positions, Scott and Ringel (1971) are concerned with a fundamenta11y different question: Are all types of articulatory events necessarily 
controlled in the same manner? They maintain the view that articulatory activity is dependent upon both open- and closed-1oop components. The articulatory productions, in their study, were done so in spite of almost total lack of information from peripheral receptors, which study supports the view of a speech mechanism operating in response to autonomous (open-loop) motor commands. But then information from the oral receptors (closed-loop refinements), they go on to say, seem to be necessary for certain labial, apical and blade refinements. The results of their study regarding the nature of motor commands are consistent with those of Liberman et a1. (1967), namely, that the open-loop component serves as the "on-off" governor and the closed-loop as the "go-to" (for accuracy) monitor. Oral sensory deprivation reduces the ability of articulators to approximate target specifications inherent in "go-to" instructions. This results in (1) less close sibilant constrictions, (2) reduced degrees of retroflexion and 1 ip rounding and (3) a slight tendency toward a more neutral vocal tract configuration during vowel production. Scott and Ringel (1971) use Henke's mode1, which explains segmental changes resulting from temporal changes of speech production, when referring to their observation that the release phase of voiceless stops was considerably prolonged in the anesthetized condition, and the voicing for the contiguous vowel was delayed compared to control examples. They conclude by saying that whether the temporal characteristics of voicing delay results from the passive result of slower supraglottal pressure release or whether the timing of glottal instruction for voicing is delayed due to incomplete information concerning stop closure, is unanswerable at present. 
Photographic Analysis. In a later study Putnam and Ringel (1972) used photography to measure labial movements produced during the experimental condition (anesthetization) and the control. The results were interpreted to explain the deviation from normal rate, accuracy and extent of lip movement with respect to open- and closed-loop control of articulation. Putnam and Ringel (1972) stated the current trend of theories of speech production emphasizes that sensory experience is a necessary entity of the neuromotor system in enabling speech movements to be finely coordinated. According to some researchers an invariability seems to exist between muscle activities during the production of /pbm/; however, Fromkin (1965) found differences in the lip muscle gestures for cognates, thus contradicting electromyographic findings of invariability between muscle activity during $/ \mathrm{pbm} /$. Putnam and Ringel (1972): found that direct photography of the lips has been effective in resolving these ambiguities and inconsistencies. So with high speed stroboscopic filming Putnam and Ringe1 (1972) described 1ip movement under normal and oral sensory deprivation and found there is evidence for distinctions between $/ \mathrm{pbm} /$ on the basis of initial lip opening rates in the release phase. Their data support the hypothesis that autonomous open-1oop controls seem to be operating in the initial portion of a word, during the vowel elements and at the end of single-word utterances, while closed-1oop systems operate via oral sensory feedback, refining ongoing articulation. It is the open-loop controls, they state, which enable speech to remain intelligible: "The fact that the subject's speech remained clearly intelligible in the block condition logically argues for some open-loop operations which can carry on 
adequately when sensory feedback is deficient." Where $/ \mathrm{p} /, / \mathrm{b} /$ or $/ \mathrm{m} /$ began a word, no major changes occurred in the manner of production, but phonemic changes did occur intervocalically, for instance, where $/ \mathrm{p} /$ followed /s/ and was produced as a fricative rather than a stop. Putnam and Ringe1 (1972) note a limitation to the idea that /pbm/ did not change because of open-loop control. The concept of closed- and open-1oop controls of lip movement in speech is complicated by the fact that the 1ip has two sources of dynamic input: a direct/active motor system and an indirect/passive one. The voluntary efforts of the 1ip and facial musculature constitute the active system, and in the passive case the lower lip is moved up to or down from the upper lip by movements of the mandible; there is a slight time delay in the lip's passive "following" movement (Putnam and Ringe1, 1972). The lower lip then "rides" passively on the mandible and is, therefore, benefited by the mandible to make closure with the upper lip to make plosive labial target contact. The sensory acuity of the temporo-mandibular joint was thought not to be affected by the anesthesia, and is thus able to "help out." Herein lies the limitation of calling the intact initial occurrences of $/ \mathrm{pbm} /$ as resulting from open-loop controls: the closing and opening of the lips while anesthetized can still benefit from "riding" on the mandible, which still has an intact sensory operating system. Therefore, the fact that no major changes occurred in the production of $/ \mathrm{pbm} /$ under oral sensory deprivation cannot be interpreted to show that speech-initial open-1oop controls are operating in the absence of labial sensory information. The passive effect (lower lip being moved relative to the upper 1 ip by compensatory movements of the mandible) of 
closed-loop speech-initial mandible activity may have aided the lips in performing adequately (but more slowly). In other words, Putnam and Ringe1 (1972) seem to be suggesting that intelligibility was maintained not simply because of open-1oop controls.

Cineradiographic Analysis: Shows Mandibular Compensation. Putnam and Ringel (1976) discuss further the relationship of the jaw to the 1ips during bilabial closure and the implications for open- or closed-loop controls in a study which serves to complement existing descriptions of orosensory deprived speech by means of cineradiographic analysis. As with the previous studies, the changes noted between nerve block and no nerve block were minor, nonphonemic in nature with speech intelligibility intact. Included in this study were descriptions of the changes regarding the lips, tongue and jaw. of most interest was the authors' explanation of the mandible's contributions to the lower lip in achieving bilabial closure. They forwarded two interpretations: (1) excessive articulatory "overshoot" (increase in articulatory amplitude) of the jaw, which is compatible with a closedloop control system and (2) compensatory factor of the jaw and other articulators, which can be seen to be not incompatible with an underlying open-loop control system. The first interpretation, involving excessive "overshooting" of the jaw due to inadequate sensory feedback from the lips regarding the status of closure, lends itself to Henke's mode1. This model shows that the normal temporal progression of speech movements is largely dependent upon peripheral feedback for the completion of one gesture and readiness for the next. Articulation does not proceed after production of stop consonants until afferent feedback 
information that closure has been achieved is received by the central nervous system. The result of this in a sensory deprived state is that the temporal progression is altered. The other interpretation states that other members of the articulatory complex can compensate to achieve a rather accurate output (Lindblom and Sundberg, 1971; Sussman, MacNeilage and Hanson, 1973; Abbs and Netse11, 1973; Folkins and Abbs, 1975). To say mandibular compensation resulted from "overshoot" due to inadequate feedback about lip closure (a closed-loop phenomenon) overlooks the observation made that the effects of right to left coarticulation (regressive assimilation) from vowel following a consonant were still apparent in the mandible position (Putnam and Ringe1, 1976). Even though the jaw was closer to the maxilla during bilabial closure, its degree of closeness was consistently related to openness of the following vowel as it had been shown under normal conditions (Sussman et a1., 1973). That is, when the following vowel was /i/ or /u/, the jaw was very close to the maxilla during the consonant; when the following vowel was $/ \not e /$ or $/ a /$, the jaw posture was consistently less close (Putnam and Ringe1, 1976). These mandibular adjustments show the potential for the jaw to likewise assist the tongue in forming the vowel itself. In fact, Putnam and Ringel (1976) cite Lindblom and Sundberg (1971) who demonstrated that "the degree of opening of a vowe1 corresponds to a position of the jaw that is optimized in the sense that it cooperates with the tongue in producing the desired area function." Putnam and Ringel (1976) saw trends in their own study that jaw adjustments were made in relation to different tongue positions, but the trends were often ambiguous. They discuss one factor in detail to 
which the ambiguity can be attributed: the unpredictable effects of nerve-block anesthetization upon structures which are neuroanatomically independent of the blocked nerve, but part of the same sensorimotor complex. This is further complicated in that the articulatory changes observed under induced 1 ingual anesthetization were due to the effects of intrinsic motor paralysis as a result of the injection procedures (Harris, 1970). Borden et al. (1973) studied the possibility of motor involvement using electromyography (EMG). Consistently depressed motor activity was revealed, seeming to confirm motor nerve involvement. However other data, in the same experiment, for the orbicularis oris and genioglossus muscles (independent of the blocked nerve) showed depressed activity in some subjects and increased activity in others. Borden et al. (1973) speculated such responses of the muscles independent of the blocked nerve indicate more than a simple interruption of a peripheral feedback loop. Putnam and Ringe1 (1976) state:

- . the data implies some form of generalized compensation and/or reorganization within the articulatory system, which may be expressed at the periphery as depression or hyperactivity in muscles neuroanatomically independent of the block effects.

Leanderson and Persson (1972) noted increased facial-muscle activity before and during speech in the mandibular blocked condition. They suggested the increased motor activity was overshooting muscle activation, possibly a result of conscious compensatory behavior under circumstances of reduced afferent information. Putnam and Ringel (19.76) note then that although articulatory movements during mandibular blocks could be resulting from the chance of motor involvement, the data of Borden et al. (1973) and Leanderson and Persson (1972) suggest that the 
articulatory behavior noted may reflect the disorganized and/or compensatory reactions of normally functioning motor elements ". . . in the total physiological response to sensory deprivation." Putnam and Ringel (1976) extended this rationale to explain the relationship between the jaw and the lips in achieving closure. They say that the lips may have contained components of conscious overshoot "in search of" adequate feedback from closure as well as the jaw. The compensatory movements of the jaw to aid the lips in obtaining closure may be interpreted then as a function of open-loop control if viewed in light of a whole sensor-motor articulatory complex, not all of which was in the nerve block condition:

Maintaining intelligible speech when there is a substantial reduction in oral sensitivity may be interpreted as evidence of some underlying open-loop speech controls, and of the utility of the remaining oral and auditory senses that support speech via closed-loop controls $\lfloor\bar{P} u t n a m$ and Ringe1, $197 \underline{6} 7$.

\section{Stuttering and Sensory Feedback}

Stuttering as Deautomatization

Mysak (1960) described stuttering as a break between storage and governor components. The term "deautomatizing" replaces "stuttering" in his mode1. That is, speech fluency is affected when there is a disturbance of the reflexive and automatic relationship between the concept and word mechanisms. Mysak hypothesized that if particular persons or various social or speaking situations (open-cycle signals) excite concepts that disturb the balance of the total system, there will be a deterioration between concept and word mechanisms, i.e., some form of stuttering may occur. Exponents of learning theory (Johnson, 
1955), psychological disintegration (Sheehan, 1958) and dysphemia (West, 1936) have been fit by Mysak into his schema. Their particular hypotheses as to etiology and their therapy were described by Mysak and regarded as being different ways of restoring automaticity or fluency to the speech system. Mysak (1960) stated that the servotherapy approach would begin by identifying what part of the client's system is primarily responsible for the break in automatic speech. For example, Mysak (1960) stated, if the clinician feels that he/she is confronted with a "controller unit" problem (West), medical assistance such as drug administration might be employed. If the client presents primari1y an open-cycle problem, then open-cycle influences (such as environmental conditions, fear, etc.) could be manipulated. Specific techniques to weaken the open-cycle fluency error signal's influences, such as Van'Riper's desensitization, nonreinforcement, ego building and self-understanding should be considered. Another approach would be to emphasize the desired "zero-error" signal by monitoring on the "integrator unit level," i.e., engaging in "verbalizing imagery" monitoring like Bluemel's phantom speech (talking with light lip and tongue movements, but without sound) and whispering techniques. By doing this, the client would be attempting to weaken the disintegrating open-loop signal by monitoring on tactile-proprioceptive channels rather than on the offending auditory channel. Mysak mentions Van Riper's voluntary control and fluent stuttering as being useful. Mysak says if it is discovered in the client that auditory anomolies or sensitivities are producing effects (stuttering) similar to those (effects) in normal persons when experimentally presented with delayed auditory sidetone, 
then efforts could be directed at developing another sensor channel as the chief monitoring system. Where phantom or whispered speech helps a system to readjust, it may be due, says Mysak, to the complete or incomplete transference of the major speech monitoring function to the tactile, or proprioceptive channel and away from the offending auditory channe1.

Discoordination of Phonation with Respiration and Articulation

Perkins (1976) noted that more stuttering occurred with voiced speech than phantom or whispered speech. Rather than view this increase in fluency as resulting from the switching away from the "offending auditory channel," Perkins stated that fluency increases because the phonatory component is no longer present. In other words, stutterers have difficulty coordinating phonation with articulatory and respiratory processes. Perkins questions as to why stutterers have more difficulty coordinating phonation with articulation and respiration than do nonstutterers:

Have they simply never learned the coordination of normal speech, are they merely at the low end of the normal distribution of endowments of skill in coordinating the speaking process, or are they below normal limits for this skill? If poorly endowed, is this characteristic transmitted genetically? What are the neurological correlates? Does the problem resemble dysarthria or apraxia; is cerebral dominance invoived; is Schwartz's (1974) analysis of the laryngeal reflex that he suspects is at the core of stuttering supported by evidence; is the auditory system involved; and if so, how?

Researchers are increasingly investigating stuttering in terms of servosystem theory with the emphasis upon the synchrony of the parameters of speech. 
Delay of Stutterers' Voice Initiation Response Time

Adams and Hayden (1976) found that the voice initiation time of "ah" for stutterers was significantly delayed compared to that of nonstutterers as a response to a presented stimuli of a series of $1000 \mathrm{~Hz}$ pure tones. The authors suggested that the delay in voice initiation time may carry over and affect stutterers' ability to quickly initiate phonation for running speech. McFarlane (1975) ran a design to test Van Riper's (1971) statement, "Mistiming could be attributed to an organic proclivity, to emotional stress, or to a malfunctioning servosystem." The purpose of McFarlane's study was to measure the Neural Response Time (NRT) to determine if significant differences existed between stutterers and nonstutterers as a function of the stimulus mode and response task. What he found was that the stuttering sample exhibited slower NRT's under conditions of auditory stimulation, thus implicating the auditory channel for contributing to stuttering. Supportive of this even further was McFarlane's additional finding that the difference in NRT's between the two samples under visual stimulation was not significant. A study done using the visual mode as discriminitive stimulus for voice initiation by Starkweather, Hirschman and Tannenbaum (1976) found that the stutterers are slower in initiating the vocalization of syllables. They stated the major theoretical implication was that whatever causes stutterers to initiate vocalization more slowly than nonstutterers is not attributable to a deviation of auditory function as maintained by Webster (1974). Webster, however, in commenting on the Starkweather et al. work stated these authors did not test the auditory channe1 but only the visua1, and stated deductions cannot be 
made about the auditory channel without involving it in the testing (Webster, 1977). However, Webster (1977) directly manipulated the auditory channel by masking the subjects with broadband noise during the presentation of the visual stimulus and found the voice initiation time of the stutterers to shorten. Therefore, the culpability of a faulty auditory channel acting possibly as the mediating mechanism for stuttering cannot be dismissed.

Webster's Auditory Interference Theory: Possible Middle-Ear Involvement

Webster and Lubker (1968) as stated in their Auditory Interference Theory (AIT) stated that the stutterer's own auditory feedback provides a source of interference with the control of speech: "Speech output control" is a hypothetical entity which represents central nervou's system mechanisms that govern the flow of neural impulses to the speech musculature (open 1oop). Speech output control integrates incoming auditory and somesthetic stimuli from motor activities which comprise the physical act of speech to regulate the release of nerve impulses which produce the motor responses of speech. Stuttering occurs when returning auditory feedback blocks the output signals of speech output control. Attenuation of auditory feedback can be seen to be a critical variable in the production of fluent speech in stutterers as seen in DAF, whispering, masking or deafness. In other words, when the intensity of stutterers' own speech is reduced or eliminated, stuttering frequency is reduced. AIT explains the adaptation effect by the servosystem mode1. On successive trials speech output control is strengthened to the extent that interference caused by returning audi- 
tory feedback is overridden, i.e., auditory feedback, what Mysak might cal1 the "offending auditory circuit," becomes important in guiding speech. It is we11 known that delayed auditory feedback can cause disruption in speech production. This can be further illustrated by what Yates had said. Yates (1965) suggested that the various amounts of speech disruption shown by different subjects during DAF could be a function of the relative degree to which subjects depend upon auditory feedback for the normal control of speech. Although Yates does not think that a convincing explanation has been put forth as to why some subjects are highly susceptible to DAF, he minimizes the importance of personality factors as playing a role and goes on to say that the "most obvious possibility is that susceptibility is a function of the degree of dependence on auditory feedback for the normal monitoring of speech as compared with dependence on kinesthetic and sensory feedback." Yates further stated that those who depend upon auditory feedback primarily, experience serious disturbance of speech with the disruption of normal auditory feedback relationships; those not so dependent upon the auditory channel would be less affected as they would then be monitoring via kinesthetic feedback which is not being disturbed. Yates stated it would be anticipated that the speech of subjects less dependent upon the auditory channel would be seriously disrupted if kinesthetic feedback were interfered with. Yates also makes the point that it is the disruption, rather than the absence, of this feedback winch produces this disturbance (something that supports the near zero prevalence of stuttering in the deaf, Webster, 1974).

Webster and Lubker (1968) have reported that the normally fluent 
subjects, during DAF alter their voice quality by increasing harshness and intensity. They say that these changes may result from the speaker's effort to decrease the relative importance of auditory feedback in speech guidance, while simultaneously increasing reliance upon oral sensory feedback. Gruber (1965) resonates the Webster and Lubker (1968) position in his analysis of stuttering behavior and DAF. He wrote:
-. does the stutterer automatically shift to the tactual and proprioceptive aspects of speech monitoring when he cannot monitor his speech auditorily? If stut- tering is linked to the way the stutterer hears his own vocal utterances, then eliminating or diminishing the use of this monitoring channel may account for his increased fluency.

A shifting from the auditory to tactile feedback may be a phenomenon which occurs in normal speech and language development.

Van Riper and Irwin (1958) maintained the auditory channel is of utmost importance during a child's early speech development period. Later, kinesthetic or tactual feedback channels replace the auditory channel as the main monitoring agent. Penfield and Roberts (1959) suggested dialect free speech is best learned at an early age, before the child switches from the auditory channel to the proprioceptive channel, while phonemic acoustic changes are being heard. Gruber (1965) stated, "It is possible that the stutterer may have failed to make the transition to the tactual and proprioceptive avenues." If the stutterer has not made the shift to primarily monitoring his speech tactually from the auditory channe1, there must be a mediating mechanism. Cherry and Sayers (1956) suggested that stuttering may be mediated by boneconducted auditory feedback. They observed the same phenomenon as 
Perkins et a1. (1976) that most stutterers can whisper fluently, and that whispered speech drastically reduces bone-conducted feedback. The mediating mechanism could possibly be interaction of the middle-ear muscles with speech production. The stapedius and tensor tympani have been shown to contract in association with speech (Shearer and Simmons, 1965). They compared the middle-ear muscle activity during speech in normal speakers and stutterers. No difference in terms of time intervals between middle-ear muscle activity and speech output was found. In both stutterers and normals impedance change was found to precede speech sound by 65 to 100 milliseconds or to occur at the same time as speech initiation. However, Webster (1974) states it is not certain from the study whether Shearer and Simmons examined the time intervals between middle-ear muscle activity and instances of stuttering which preceded what might be considered to be speech output.

Shearer (1966) studied the impedance bridge changes during the speaking behavior of five stutterers and found a difference between this activity in stuttered and fluent speech. The impedance changes during stuttering on the initial /p/ did not always reflect the sound level of speech in a precise manner. Shearer (1966) reports that this phenomenon occurs in fluent speech also but is more readily demoristrated in stuttering. Webster refers to Shearer's strip charts and notes the middle-ear activity occurring at the same time as stuttering rather than before stuttering. This writer's examination of Shearer's strip chart concurs with this observation.

Webster and Lubker (1968) suggested that the reflex responses of the middle ear may be the mechanism that mediates the nature of 
interaction between components of auditory feedback. They stated that the middle-ear mechanism may be able to meet the qualification of such a mechanism. Any mechanism postulated to mediate the interaction between air- and bone-conducted feedback in stutterers must not be a steady state property of the auditory system of the stutterer. Rather it must show variance of action across the range of stuttering severity and conditions.

Stuttering Viewed As Central Auditory Dysfunction

Additional evidence that auditory functioning in stutterers is different than that of nonstutterers and, therefore, may be implicated as a factor contributing to the onset and maintenance of stuttering can be found from a most recent study by Hall and Jerger (1978). They assessed central auditory function in stutterers and nonstutterers with a battery of clinically valid tests: The objective was to compare the relative pattern of test performance in stutterers to that of a control group of nonstutterers. Hall and Jerger cautioned that conclusions cannot be drawn from studies employing a single auditory test, as isolated test results obtained on the stuttering group are characterized by inconsistencies. They go on to say:

With this limitation in mind, it is reasonable to conclude that, as a group, the stutterers did present evidence of a central auditory deficiency. More specifically, the pattern of test results suggests disorder at the brainstem leve1.

The researchers emphasize the subtlety of the disorder: "Although acoustic reflex thresholds in the stuttering group were normal, this finding does not detract from the possible significance of their decreased acoustic reflex amplitudes." They state that the depressed 
performance of the stuttering group becomes apparent only when compared with a carefully matched control group.

If the auditory feedback loop is the faulty feedback channel, and if the stutterer is using this faulty channel as the primary monitoring agent during speech production, then with elimination of oral sensory feedback, the frequency of stuttering would be expected to be increased, as the stutterer would be relying solely upon auditory feedback for speech gesture guidance.

\section{Closed-Open-Loop Paradigm}

Hutchinson (1973) used nerve block anesthesia on six male stutterers to investigate the effects of oral sensory deprivation upon stuttering behavior. He discovered that oral sensory deprivation resulted in more frequent and severe disfluency. He interpreted these results as evidence for the hypothesis that stuttering involves both open- and closed-loop regulation processes. He stated: "Results suggest that the basic stuttering moment is pre-programmed but certain feedback dependent refinements are operative to mitigate or defeat the negatively conditioned open-loop commands." Hutchinson is using openloop to refer to central motor programming without peripheral feedback and closed-loop refers to sensory information vital for the orderly and accurate execution of motor events. A parallel can be seen here between the oral sensory deprivation studies of articulation production and stuttering behavior. The articulation studies demonstrate the importance of orosensory feedback articulatory refinements, but not intelligibility. With stuttering behavior, oral sensory deprivation prevents accurate execution of articulatory adjustments; hence, 
normalization (reduction of the stuttering) is reduced, i.e., the suggested pre-programmed open-loop event of stuttering (Hutchinson, 1973) is not being inhibited or controlled. If the stutterer has a faulty auditory feedback system, he would stutter more when deprived of proprioceptive, tactile feedback during anesthetization because of the forced reliance upon the faulty auditory channel, hypothesized Hutchinson.

Articulation Proficiency of Stutterers Versus Nonstutterers

Possibly another way to examine whether or not stutterers monitor speech auditorily rather than orally would be to compare the articulation proficiency of stutterers and nonstutterers while in a state of oral sensory deprivation. If the stutterers are relying primarily upon auditory feedback for speech guidance and the nonstutterers are not, then it might be expected that the stutterers' articulation performance would be better than that of the nonstuttering group, which relies more upon the now eliminated oral sensory feedback channel for phonetic get-to closed-1oop direction. The stutterer may be stuttering more because what he depends upon to mitigate the negatively conditioned open-loop commands is gone, oral sansory monitoring, but his articulation errors may be less for the very same reason he stutters, because he monitors speech primarily with the auditory channel which is, of course, not affected during the experimental condition. 
CHAPTER III

METHODS AND PROCEDURES

Methods

\section{Subjects}

Six adult male stutterers and six adult nonstutterers (four male, two female) were the subjects for the study. Those in the stuttering sample with an age range of 23 to 45 years acknowledged themselves to be stutterers who admit to phoneme, word and situation fears. Four had been through a fluency program, and two were presently enrolled in one. The minimum pre-fluency program disfluency rate in conversation was 4 per cent. None of the stutterers exhibited any other communicative disturbance or regional dialect at the time of the experiment. They all reported a negative history of neurological problems. The nonstuttering sample, age range 25 to 55 years, exhibited no speech or hearing problems or regional dialect. As the subjects participating in the study, both stutterers and nonstutterers, were selected in part because they exhibited normal articulatory proficiency, a formal articulation pre-test was thought unnecessary and, therefore, was not done.

All the subjects participating in the study were fully cognizant of the experimental procedures. To demonstrate this awareness all subjects were required to sign a subject-experiment agreement form, which contained a description of the anesthetization procedures to be performed by the dentist, the risks involved and the precautionary 
steps taken to minimize those risks (Appendix A). In addition to this, a signed statement was required from each subject's own dentist attesting to the fact that the subject had no history of idiosyncratic reaction to anesthetization of the oral region (Appendix B).

\section{Instrumentation}

Drs. Alan Clarke, D.M.D., or Frank McKeown, D.M.D., imposed a trigeminal nerve block through routine dental procedures. Specifical1y, bilateral mandibular and incisive foremen injections were administered. Additionally, a topical anesthetic spray was applied to the entire surface of the hard palate.

For the recording of the speech sample a Sony reel to reel TC with a hand held microphone at a distance of approximately 6 inches from the subject's mouth, was used at the speed of $7 \frac{1}{2}$ inches per second, set at the loudness leve 5 using 3 inch Realistic audio tape.

\section{Judges}

The judges for this study were three cartified speech and language pathologists. Their task was to listen to each tape on which a subject produced 50 words at 5 second intervals and indicate whether the word was produced correctly or was in error, and if in error, to identify the nature of the error (omission, substitution, distortion, addition). In the case of distortions, an additional judgment as to the degree of distortion was made based on such evaluative procedures as used with administration of the Photo Articulation Test (PAT). These scoring procedures were presented to them in written form (Appendix C). Recording of this evaluative data was done upon data recording 
sheets (Appendix D). The judges listened to all fifty word productions of one subject before listening to the word productions of the next subject. To counterbalance an order effect, the order of presentation of the subject tapes was presented randomly. Each judge was familiar with and used the same articulation error notation system, including the PAT system, for describing the degree of distortion.

Intra-judge reliability was determined by re-playing two of the twelve tapes for each judge, immediately after the twelfth tape was played. The same two tapes were re-played for each judge. Reliability determination was then made using percentage of agreement as criterion.

\section{Procedures}

\section{Setting}

All testing occurred in the offices of Drs. Alan Clarke, D.M.D., and Frank Mckeown, D.M.D.

\section{Data Gathering}

The subject was seated in the dental chair with ten different plastic shapes placed on a tray directly in front of him. It was explained to the subject that the identical objects to the ones being viewed would be placed one at a time into his mouth (the order was randomized) without being viewed. After palpating the plastic shape with the tongue, the subject was then to identify it by pointing to its duplicate among those in view of the subject. After the dentist performed the anesthetization procedures, the plastic shapes were again presented as they were before the imposition of the nerve block injections. When the subject could identify no more than two of the ten 
plastic shapes, it was determined that the experimental condition was imposed and the speech stimulus was presented; a recording form was used (Appendix E).

The Tikofsky word list for intelligibility determination was presented. Each of the fifty words was typed on file envelope labels and placed centrally upon light green $3^{\prime \prime} \times 5^{\prime \prime}$ unlined index cards. The cards with the word to be produced by the subject were presented visually by hand in front of the subject's field of vision one at a time at five-second intervals. The order of presentation was randomized using a random order table. The tape recorder was turned off after utterance of the fiftieth stimulus card, ending the subject's participation.

\section{Data Analysis}

The data were analyzed in terms of means, scores and standard deviations. The small sample $t$ test was used to determine if there was a significant difference in the articulation proficiency, as measured by the number of error scores, between the stuttering and nonstuttering samples while in a state of oral sensory deprivation. Additionally, four $t$ tests were performed to determine if there was a significant difference between the stutterers and the nonstutterers regarding the four types of errors identified by the judges: distortions, omissions, substitutions and additions. 
CHAPTER IV

RESULTS AND DISCUSSION

\section{Results}

To determine if an imposed oral sensory deficit hinders articulatory proficiency more in a nonstuttering sample than in a stuttering sample the mean and standard deviation were computed for the stuttering and nonstuttering samples. These scores were obtained by counting the number of errors the three judges identified for each subject, and then finding the mean for that subject. These averages then were used to compute the mean for each sample. As seen in Table I, there was a difference in the number of errors produced between stutterers and nonstutterers in the state of induced oral sensory deprivation. Out of

\section{TABLE I}

MEAN SCORES, STANDARD DEVIATIONS, AND VALUE OF $t$ AT .05 LEVEL OF SIGNIFICANCE FOR NUMBER OF INCORRECTLY ARTICULATED WORDS AS PRODUCED BY STUTTERERS AND NONSTUTTERERS DURING INDUCED ORAL SENSORY DEPRIVATION

\begin{tabular}{lcccccc}
\hline \multicolumn{1}{c}{ Sample } & $\begin{array}{l}\text { 非 of } \\
\text { Items }\end{array}$ & $\begin{array}{c}\text { Range of Scores } \\
\text { (Errors) }\end{array}$ & Mean & S.D. & $t$ & d.f. \\
\hline Stutterers & 50 & $13.33-24.33$ & 20.11 & 5.49 & & $\begin{array}{l}\text { 0.866 } \\
\text { N.S.) }\end{array}$ \\
Nonstutterers & 50 & $4.33-22.33$ & 17.05 & 6.68 & & 10 \\
\hline
\end{tabular}


the fifty words from the Tikofsky intelligibility word list, the mean score for the nonstuttering was 17.05 with a standard deviation of 6.68 , while the mean score for the stutterers was 20.11 with a standard deviation of 5.49. Articulation proficiency was not hindered more in the nonstuttering sample than in the stuttering sample, contrary to what was expected. The overall mean differences show the stutterers' articulatory ability to be less proficient than the nonstutterers. To determine if this difference was statistically significant, $t$ tests were performed on the mean scores of the stuttering and nonstuttering samples. This value of $t$ appears in Table $I$ and indicates there is no statistical significance for this noted difference ( $p \quad .05)$.

To determine if the nature of the errors differs between the two samples, a comparison was made by type of articulatory error as identified by the judges. Table II illustrates this in terms of the percentages of each of the four types of error for both samples. The nonstutterers exhibited a lower percentage of distortion and addition errors than the stutterers: 68.7 per cent to 77.7 per cent and 3.9 per cent to 7.9 per cent, respectively. However, the nonstutterers had more omissions and substitution errors than the stutterers: 7.5 per cent to 3.8 per cent and 20 per cent to 10.1 per cent, respectively. To determine if these differences in types of articulatory errors between samples was significantly different, $t$ tests were performed on the mean scores of the two samples for each type of articulatory error. Table III shows that the $t$ values were not significant for the stuttering and nonstuttering sample regarding each type of articulatory error. 


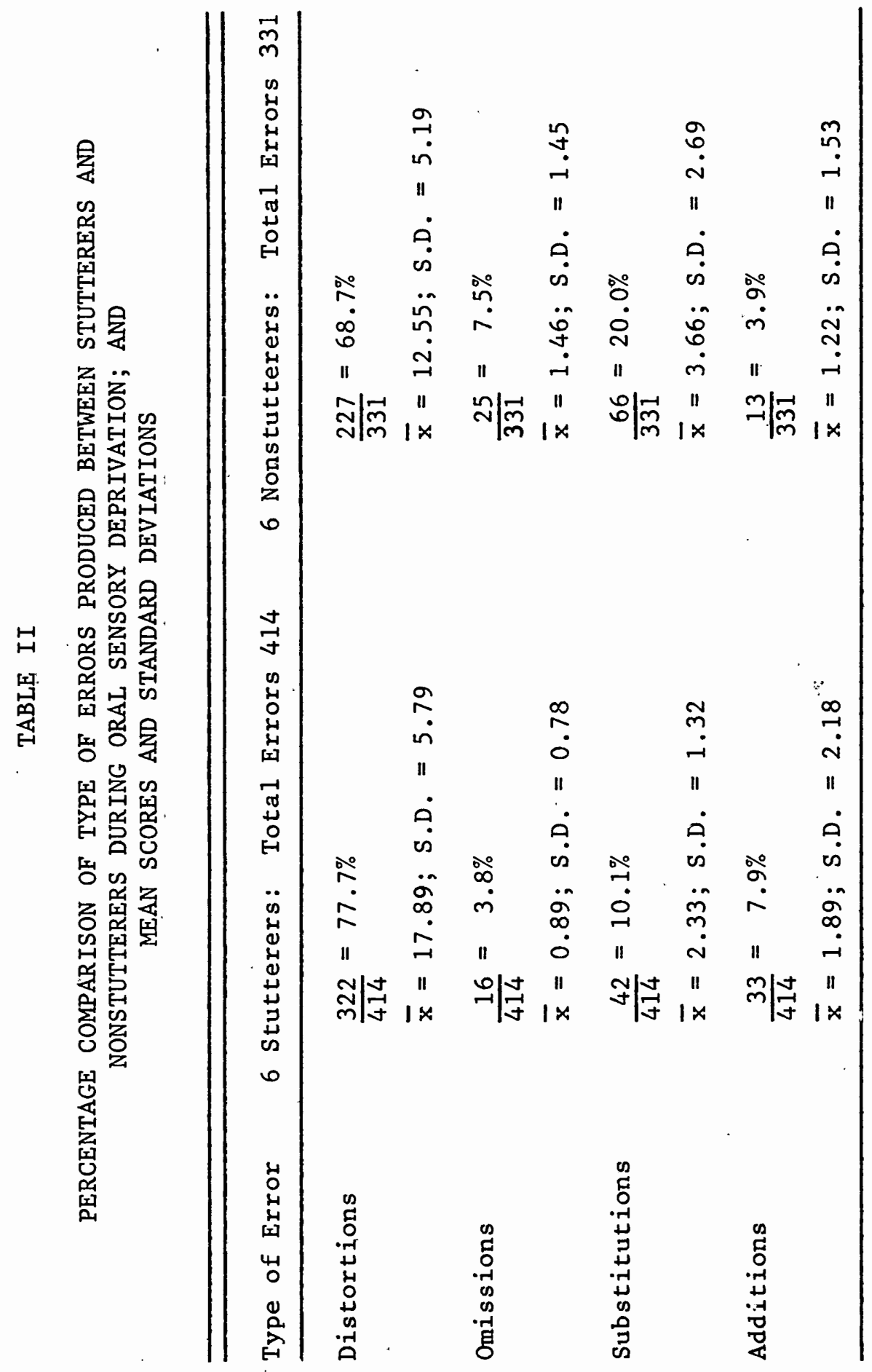


TABLE III

VALUES OF $t$ RELATIVE TO TYPE OF ARTICULATORY ERROR BETWEEN

STUTTERERS AND NONSTUTTERERS DURING ORAL

SENSORY DEPRIVATION

\begin{tabular}{lcccc}
\hline $\begin{array}{l}\text { Statistical } \\
\text { Measure }\end{array}$ & Distortion & Omission & Substitution & Addition \\
\hline t value & $1.68 *$ & $0.73 *$ & $1.09 *$ & $0.61 *$ \\
d.f. & 10 & 10 & 10 & 10 \\
\hline
\end{tabular}

$$
*(\mathrm{p}>.05)
$$

\section{Discussion}

Prior to the discussion of the hypothesis implied from the stated questions in Chapter I, judge reliability will be noted. There was not a particularly high inter-judge reliability. As seen in Table IV, all three judges were in 100 per cent agreement (averaged) as to whether speech productions elicited from the subjects were correct or incorrect 49.6 per cent of the time for stutterers and 53.6 per cent for the nonstutterers. Higher percentages of agreement were obtained comparing any two judges. The highest percentage of agreement was achieved with judges 1 and 2: 75.3 per cent for stutterers and 73 per cent for non-

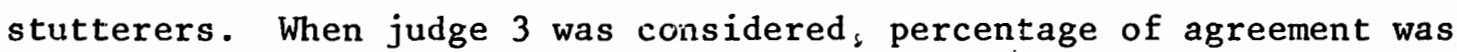
less. A stabilizing factor was that the presentation of the subjects' tapes was randomized, and there was essentially, no change in percentage of agreement of the judges for stutterers as compared to nonstutterers. Although the third judge's scoring was at variance with judges 1 and 2 , judge 3 had the highest intra-reliability score (90 per cent) compared 
TABLE IV

JUDGE INTER-RELIABILITY: ALL THREE IN 100 PER CENT AGREEMENT

\begin{tabular}{ccc}
\hline & \\
\hline Judges & Stutterers & Nonstutterers \\
\hline Judges 1, 2,3 & $49.6 \%$ & $53.6 \%$ \\
Judges 1,2 & $75.3 \%$ & $73.0 \%$ \\
Judges 1,3 & $59.0 \%$ & $68.0 \%$ \\
Judges 2,3 & $64.3 \%$ & $66.3 \%$ \\
\hline
\end{tabular}

to judges 1 and 2: 74 per cent and 73 per cent, respectively. The high intra-reliability score for judge 3 resulted from more responses to be judged as being norma1.

These relatively low reliability scores may be attributable to the pecculiarity of the articulation errors elicited from the subjects in the nerve block condition. For example, although the judges were instructed to determine if the word production was incorrect or correct and then identify the error, if any, in terms of the usual (distortion, omission, substitution, addition) descriptions, there were other deviations in speech (prosodic features) resulting from anesthetization. These prosodic features did not fit into these four classifications. These "unaccourted for" variations in the subjects' productions could have been more influential on one judge than another or others in their determining if the production was in error. See Appendix $F$ for each judge's performance.

Perhaps the degree of anesthetization was a contributing factor for some subjects to exhibit these prosodic features. Some subjects 
needed more anesthesia to meet the criterion which established the subject to be in an induced state of oral sensory deprivation. The subjects were not presented with the speech materials until they could identify no more than two plastic forms correctly (Appendix E). Meeting this criterion, each subject failing to identify at least eight of the ten plastic shapes, does not necessarily mean that the same degree of oral sensory deprivation for each subject was achieved. Additiona11y, the time required to qualify as being anesthetized varied. There might have been a correlation between the time required to meet the anesthetization criterion and the degree of the anesthetization. Those subjects who "resisted" entering the sensory deprived state (their ability to identify more than two of the ten shapes correctly after the injections) were reinjected. These subjects may very we11 have obtained a deeper state of anesthetization than those subjects who more quickly arrived at the experimental state. By passing anesthetization criteria quickly they avoided the additional injections. The prosodic features may have been different for subjects who might have achieved a lesser state of oral sensory deprivation. What the judges perceived to be correct or incorrect regarding articulation may have been adversely influenced by the perception of the prosodic elements. However, since the stutterers and nonstutterers were judged in random order (randomized from a random order table), and the variance of the degree of anesthetization could not be controlled or restricted to one sample or the other, this investigator believes that the results of this study were not due simply to the noted variance in judging nor the possible differing degrees of anesthetization for various individuals within the 
samples .

This study's purpose was to investigate Gruber's (1965) contention that the stutterer's development "has become arrested at the auditory level of speech monitoring and has failed to make the transition to the tactile and proprioceptive avenues." Van Riper and Irwin (1958) considered a shift in the monitoring of speech from auditory to oral sensory channels after articulation is stabilized:

- . younger (under 8 or 9) children are monitoring their articulation mainly by means of the auditory feedback. As their new articulatory skills become stabilized, they turn over the monitoring to the kinesthetic and tactual feedback systems with less interference to the thought process.

Empirical studies have strengthened this contention. Fucci and Robertson (1971) found there was a relation between oral stereognosis to articulatory proficiency in older children (12 to 16$)$. In another study Madison and Fucci (1971) found that speech-sound discrimination, not oral stereognosis, was related to articulatory performances in younger children (first graders). Nesbitt (1974) found that lingual discrimination improved with age. The results of these studies strengthens the Van Riper and Irwin (1958) hypothesis that the importance of auditory feedback lessens with the stabilization of articulation skills in favor of the oral sensory feedback systems. This investigator's study integrated data from the articulation studies regarding oral sensation of normal speakers with the servotheory of stuttering by investigating the articulatory proficiency of stutterers compared to normals in a state of oral sensory deprivation. The inferred hypothesis was that because the nonstutterers may be depending more upon oral sensory feedback for articulatory proficiency to a greater extent than 
stutterers, who may have failed to make the shift from the auditory channel to the oral sensory channel, the nonstutterers would exhibit less articulatory proficiency (more errors). The specific questions were:

1. Does an imposed oral somesthetic feedback deficit hinder articulatory proficiency more in a nonstuttering sample than in a stuttering sample?

2. If the articulation proficiency is deficient in both samples, does the nature of the errors differ between the two samples?

The answers to these questions were:

1. Articulatory proficiency of nonstutterers was not more impaired than stutterers.

2. The nature of the errors did not significantly differ for either of the samples.

From the results it may be stated that stutterers do monitor their 'speech as nonstutterers do (they have shifted to oral sensory feedback channels) as there was no difference in the articulatory proficiency between the stutterers and nonstutterers.

The data could be interpreted differently however. Studies comparing articulatory proficiency with oral sensory feedback have only considered tactile feedback in their oral stereognostic testing (the identification of plastic shapes). There are other components of oral sensory feedback not definitely eliminated in states of oral sensory deprivation, kinesthesia and/or proprioception. Gammon et a1. (1971) initially thought that speech intelligibility remained intact during oral sensory deprivation states because of kinesthesia. Although Schliesser and Coleman (1968) claimed that nerve block anesthetization eliminated kinesthesia, as they determined by introducing movement to 
the tongue by manipulating it with forceps, Gammon et al. (1972) did not accept the equation of the mechanical manipulation of a passive tongue with the tongue movements resulting from the speaker's own muscles. Gammon et a1. (1972) stated talkers are usually not deprived of all sense of tongue position despite deep anesthetization. The maintenance of speech intelligibility, they state, may be attributed to proprioception rather than kinesthesia:

Until the extent and import of such neuro-muscular spindle feedback is determined and until there is further evidence concerning the effect of anesthetic upon such different neuronal pathways, one cannot rule out proprioceptive sensation in the maintenance of articulation control under anesthetization /Gammon et a1., 1972 7 .

Kozhevnikov and Chistovich (1966) provide an aIternate explanation for the lack of phonemic change in articulatory proficiency. Motor responses become so overlearned that sensory deprivation does not significantly interfere with articulation. Also, Madison and Fucci (1971) refer to the internalization of articulation as an automatic motor act. But lending further support to the Gammon et a1. (1972) position is Mysak (1976). Mysak's (1976) statement implies that there is an important oral monitoring system still operating for the talker while in a state of oral sensory deprivation: "Anesthetizing the articulators is a way of eliminating tactile feedback. The application of vibrators to the articulators may mask proprioceptive feedback." In other words, it seems that Mysak (1976) is implying that proprioceptive feedback is intact during the nerve block condition. From these theoretical and empirical considerations this writer contends that the findings of this study can be interpreted to suggest that stutterers do monitor speech production orally as do nonstutterers for touch perception and, 
therefore; have made the shift from the auditory to the tactilekinesthetic feedback channels, as determined by measuring articulatory proficiency. Assuming then that stutterers have already made the shift to the tactile-kinesthetic feedback channel, as interpreted from the results of this study, and that stutterers should, therefore, not need to be "forced" to make this shift, one needs to ask what then explains the improvement in the fluency of stutterers when DAF or masking is employed?

When DAF is employed, that which seems to be most perceptively altered is rate of speech (Goldiamond, 1965; Webster and Lubker, 1968). Timing of articulatory gestures (movements) are probably enhanced through the slower speech production when auditory feedback is altered via DAF. With masking the stutterer may be monitoring more normally the rhythm of speech (Mysak, 1976). Quoting Mysak (1976):

Such auditory masking may also result in certain stutterers becoming more fluent. Possible explanations for this effect may be . . . the elimination of a hypersensitive sensor for control and monitoring of speech rhythm. . . .

Hence DAF and masking may be "forcing" the shift for the stutterer from his faulty auditory channel to a then more attended to proprioceptive system of the oral sensory feedback channel.

Therefore, Gruber's (1965) conjecture that the stutterer's deve1opment "has become arrested at the auditory level of speech monitoring and has failed to make the transition to the tactile and proprioceptive avenues," cannot be totally discounted by the results of this study. There are now data, as provided by the results of this study, supporting the idea that the stutterer has already shifted to the tactilekinesthetic avenues for speech monitoring, but may not be sufficiently 
shifted to the proprioceptive component of the oral sensory feedback channe1. 
CHAPTER V

SUMMARY AND IMPLICATIONS

Summary

The purpose of this thesis was to determine if stutterers monitor speech production differently than nonstutterers while in a state of oral sensory deprivation. The specific questions asked were:

1. Does an imposed oral somesthetic feedback deficit hinder articulation proficiency more in a nonstuttering sample than in a stuttering sample?

2. If the articulation proficiency is deficient in both samples, does the nature of the errors differ between the two samples?

The answers to these questions were:

1. Articulatory proficiency of nonstutterers was not more impaired than stutterers.

2. The nature of the errors did not significantly differ for either of the samples.

The comparison of the monitoring abilities of speech in stutterers and nonstutterers has become relevant in investigating the nature of stuttering. Researchers (Gruber, 1965; 1970; Webster and Lubker, 1968; Goldiamond, 1965; Mysak, 1960, 1976; Trotter, 1967) have established that stuttering behavior can be reduced with masking and/or DAF. Gruber (1965) and Mysak (1976) have offered as one of the possible explanations for this effect to be a "forced" shift in the monitoring of speech from a possibly faulty auditory feedback channel to a more efficient tactile-proprioceptive sensor. Van Riper and Irwin (1958) 
stated that children acquiring speech and language initially monitor their speech auditorily (younger than 8 and 9) and then shift to oral sensory feedback for speech monitoring when articulation skills become stabilized, thus enabling the auditory channel to monitor further language acquisition. In light of the fluency effect of auditory feedback manipulation with stutterers, explained in terms of a "forced" monitoring shift to the tactile-kinesthetic-proprioceptive sensory systems, and the idea that normally developing children spontaneously shift away from auditory monitoring to the oral sensory systems, Gruber (1965) suggested stutterers may not have made this shift.

This writer hypothesized that the present investigation of nonstutterers' articulation would be less proficient than the stutterers' since the nonstutterers could no longer be relying upon oral sensory feedback in a state of oral sensory deprivation. Further, the stutterers' articulation proficiency would be expected to be less affected by the anesthetization if they are depending less upon the tactilekinesthetic-proprioceptive feedback and more upon auditory sensory feedback. The relationship between articulatory proficiency and induced oral sensory deprivation states has been researched and also was reviewed.

Oral anesthetization procedures, in this study, consisted of the administration of bilateral mandibular nerve block injections by two dentists in their dental offices in Portland, Oregon, in the early evening after regular office hours. Six male stutterers, whose ages ranged from 23 to 45 years, and six. nonstutterers, whose ages ranged from 25 to 55, four male and two female, participated as subjects. 
After passing criteria to determine the effectiveness of the anesthetization, the subject was presented the Tikofsky intelligibility word list, individually, as typed on $3^{\prime \prime} \times 5^{\prime \prime}$ index cards, which he was to read, while being recorded auditorily.

Three licensed speech and language pathologists serving as judges listened separately to each tape. The tapes of both samples were combined and randomized. Judgments made were (1) right/wrong and (2) identification of error (distortion, omission, substitution, addition). Through the use of a t test, the results showed no significant difference in articulatory proficiency between the stutterer and nonstutterer at the .05 level $(p>.05)$ of confidence. Neither was there a significant difference between samples for the types of errors committed.

These results suggested that both stutterers and nonstutterers monitor speech the same way. The expectation that the nonstutterers' articulation would be less proficient was not demonstrated; hence, from this study it cannot be said that stutterers monitor their speech less orally than nonstutterers. Another interpretation was offered, however.

The observation that there was no significant difference in articulatory proficiency between the two samples while in the state of oral sensory deprivation does not necessarily lead to the discarding of the idea that stutterers and nonstutterers monitor speech different1y. It was discussed that the difference could possibly lie in the proprioceptive system (or component) of oral sensory feedback, as it was realized after completing the study that anesthetization of the articulators eliminates tactile, but not necessarily proprioceptive feedback 
(Gammon et a1., 1972; Mysak, 1976).

Therefore, it may be said that loss of tactile feedback for both nonstutterers and stutterers results in minor articulation errors while in an oral sensory deprived state. One may still wonder if the difference in speech monitoring (if any) between stutterers and nonstutterers is in the proprioceptive system of oral feedback rather than in the presumed tactile feedback system.

\section{Implications}

\section{$\underline{\text { Clinical }}$}

The conclusions of this study indicate that the stutterer will experience fluency if he/she can learn to replicate speech similar to the manner produced when DAF or the auditory masker is utilized. The effect of DAF and/or the masker seems to be to "force" the stutterer to monitor speech proprioceptively rather than auditorily. Proprioceptive monitoring suggests that the talker "tunes in" to the manner in which the speech mechanism is moving. This is to say that speech is not static (not produced one syllable pulse or articulatory gesture at a time) but is dynamic or ongoing after initiated. The monitoring of ongoing speech implies that certain adjustments are being made. For instance, the talker does not produce a syliable one phoneme completely before beginning the next one. Rather the talker co-articulates the phonemes in order to produce the acceptable syllable. For example, cup is produced $/ \mathrm{k} \wedge \mathrm{p} /$, not $[\mathrm{k}][\wedge][\mathrm{p}]$. To achieve this the talker must be monitoring the dynamic production of individual speech sounds. The mechanism for this, co-articulation, enables up to fifteen phonemes 
to be produced per second (Van Riper, 1971); therefore, speech must be an automatic process. Any "adjusting" of the speech system would necessarily have to be, to a considerable extent, "self-adjusting" (closed-1oop in manner) due to the speed of articulatory gesturing. The talker can only hope to have an overall "feel" for running speech (proprioception) rather than be monitoring phonemes individually. Proprioceptive feedback for intelligible running speech (Gammon et al., 1972) implies a sense of coordination of three major components of speech: respiration, phonation and articulation, as Perkins (1976) discussed.

Coordination for. Initiation of Speech and Feedback Considerations

The initiation of speech requires the talker to coordinate (or time) the starting and appropriate sequencing of respiration, phonation and articulation. Since the talker moves from a static state prior to the initiation of a speech event, the feedback being experienced for this may not be closed-loop or "self-regulatory," but open-loop since the speaker is "doing nothing" acoustically before speech is initiated. Some activation must occur. This "first moment" of speech production must accurately time respiratory and phonatory events with articulatory gesturing. Important to the correct execution of this open-loop (on-off) event is the participation of the auditory feedback system.

Middle-Ear Muscle Component of Fluent Speech

The contraction of the middle-ear muscles has been shown to precede the production of sound (Salomon and Starr, 1963; Shearer and Simmons, 1965). Shearer and Simmons (1965) suggested that as the 
occurrence of middle-ear muscle activity is activated before speech output, this would indicate that the middle-ear muscle activation occurs relatively concurrently with the speech musculature. Although the mechanism responsible for contraction of the middle-ear muscles during speech is unknown, there are hypotheses. One of them states that the stapedius and tensor tympani muscles might be stimulated to contract relatively concurrently with the speech musculature by an unknown nonacoustic reflex arc (McCall and Rabuzzi, 1973). These researchers found that the middle-ear muscles can be activated to contract on a reflexive level by electrical stimulation of the internal laryngeal nerve. It seems to this writer these findings underscore the importance of proprioceptive monitoring for the execution of fluent speech. This is because there must be a synchronization of the initiation of speech musculature movement, with corresponding auxillary functioning of the auditory channel, if the middle-ear muscles and the initiation of sound occur relatively concurrently. Seen in this light, the masker may "force" the stutterer to start this process with closer monitoring for the timing of the initiation of phonation with the speech musculature corresponding to the respiratory and articulatory aspects of speech initiation.

Therapies designed to construct the specific, conscious manipulation of the rate, duration and positioning of the articulators in coordination with the initiation of the onset of voice would seem to fit most closely to what may happer automatically to the speech of the stutterer realizing fluency when speech monitoring is shifted from the auditory to the proprioceptive channel by DAF or the masker. Perhaps 
the conscious monitoring of the initiation of voicing simulates the open-loop command (on-off) possibly needed to trigger middle-ear muscle activation with ongoing speech musculature.

$\underline{\text { Research }}$

A replication of this study is suggested with some modifications. If judges were to be used, a higher reliability would probably result if they were familiarized with the speech of persons in a state of deprived oral sensation. A spectographic analysis would eliminate human judgment, as it would provide objective data. Other parameters of speech could be studied, comparing stutterers to nonstutterers while in an oral anesthetized state, regarding prosodic feature differences such as intensity, fundamental frequency and syllable durations.' If articulatory proficiency were to be tested again, an articulation test could be used for a more systematic evaluation of phonetic disturbance of the stutterers and nonstutterers while anesthetized.

Another idea would be to use only stutterers as subjects and attempt to obtain relative differences regarding speech-sound discrimination and stereognosis. The subjects could be put into two groups:

(1) those relatively better at speech-sound discrimination and (2) those relatively better at stereognosis. After subjecting the subjects to a state of oral sensory deprivation, testing could be done to determine differences, if any, in the number of articulatory errors produced.

Finally, elimination of proprioception would be interesting. Apparently this would have to be done by applying some kind of vibrators to the articulators, in addition to the usual anesthetization 
procedures. 


\section{SELECTED BIBLIOGRAPHY}

ABBS, J. H., and NETSELL, R. W., Coordination of the jaw and lower lip during speech production. Paper presented at Annual Convention of American Speech and Hearing Association, Detroit, Michigan (1973).

ADAMS, M., and HAYDEN, P., The ability of stutterers and nonstutterers to initiate and terminate phonation during nonspeech activity. J. Speech Hearing Res., 19, 290-296 (1976).

BARBARA, D. A., Stuttering. London: Hutchinson Medical Publications (1958).

BORDEN, G. J., HARRIS, K. S., and CATENA, L., Oral feedback II: An electromyographic study of speech under nerve-block anesthesia. J. Phonet., 1, 297-308 (1973).

CHERRY, C., and SAYERS, B., Experiments upon the total inhibition of stammering by external control and some clinical results. J. Psychosomatic Res., 1, 233-246 (1956).

COLEMAN, R. O., and SCHLIESSER, H. F., Comment on "Articulation and stress/juncture production under oral anesthetization and masking." J. Speech Hearing Res., 15, 669-672 (1972).

CORIAT, I. H., Stammering: A psychoanalytic interpretation. J. Nervous and Mental Disorder Monographs, no. 47 (1928).

FAIRBANKS, G., Systematic research in experimental phonetics: 1. A theory of the speech mechanism as a servosystem. J. Speech Hearing Dis., 19, 133-139 (1954).

FOLKINS, J. W., and ABBS, J. H., Lip and jaw motor control during speech: Responses to resistive loading of the jaw. J. Speech Hearing Res., 18, 207-220 (1975).

FROMKIN, V., Location of 1 ip muscles by electromyography. Work. Pap. Phonet., 2, Los Angeles: Univ. of California, 51-54 (1965).

FUCCI, D. J., and ROBERTSON, J. H., "Functiona1" defective articulation: An oral sensory disturbance. Perceptual and Motor Skills, $33,711-714$ (1971).

GAMMON, S. A., SMITH, P. J., DANILOFF, R. G., and KIM, C. W., Articu1ation and stress/juncture production under oral anesthetization and masking. J. Speech Hearing Res., 14, 271-282 (1971). 
GAMMON, S. A., SMITH, P. J., DANILOFF, R. G., and KIM, C. W., Comment on Schliesser and Coleman's comment. J. Speech Hearing Res., 15, 671 (1972).

GOLDIAMOND, I., Stuttering and fluency as manipulable operant response classes. In L. Krasner and L. U11man (Eds.), Research in Behavior Modification: New Developments and Implications. New York: Holt, Rinehart and Winston (1965).

GRUBER, L., Sensory feedback and stuttering. J. Speech Hearing Dis., $30,378-380(1965)$.

., Reply to "A feedback model of the stuttering problem-An engineer's view." J. Speech Hearing Dis., 35, 309 (1970).

HALL, J. W., and JERGER, J., Central auditory function in stutterers. J. Speech Hearing Res., 21, 324-337 (1978).

HARRIS, K. S., Physiologic measures of speech movements: EMG and fiberoptic studies. In Proceedings of the Workshop: Speech and the Dentafacial Complex: The State of the Art, ASHA Reports 5. Washington, D. C.: American Speech and Hearing Association, 271$282(1970)$.

HOERR, NORMAND L., and OSOL, ARTHUR (Eds.), Blakiston's New Gould Medical Dictionary (2nd ed.) New York: The Blakiston Division, McGraw Hill Book Company, Inc. (1956).

HORII, Y., HOUSE, A. S., LI, K. P., and RINGEL, R. L., Acoustic characteristics of speech produced without oral sensation. J. Speech Hearing Res., 16, 67-77 (1973).

HUTCHINSON, J. M., The effect of oral sensory deprivation on stuttering behavior. Doctoral dissertation, Purdue Univ. (1973).

JOHNSON, W., Stuttering in Children and Adults. Minneapolis: Univ. of Minnesota Press (1955).

KOZHEVNIKOV, V. A., and CHISTOVICH, L. A., Speech: Articulation and perception. Washington, D. C.: Joint Publications Research Service, U. S. Bureau of Commerce, 30, 543 (1966).

LEANDERSON, R., and PERSSON, A., The effect of trigeminal nerve block on the articulatory EMG activity of facial muscles. In R. Leanderson (Ed.), On the Functional Organization of Facial Muscles in Speech. Stockholm, Sweden: Departments of Otololaryngology and Clinical Neurophysiology, Karolinska. Sjukhuset, 1-8 (1972).

LIBERMAN, A. M., COOPER, F. S., SHANKWE ILER, D. P., and KENNEDY, M., Perception of the speech code. Psychological Rev., 74, 431-463 (1967). 
LINDBLOM, B. E., and SUNDBERG, J. E. F.; Acoustical consequences of lip, tongue, jaw, and larynx movement. J. Acoust. Soc. Amer., 50, 1166-1179 (1971).

McCALL, G. N., and RABUZZI, D. D., Reflex contraction of middle-ear muscles secondary to stimulation of laryngeal nerves. J. Speech Hearing Res., 16, 56-61 (1973).

McCROSKEY, R., The relative contributions of auditory and tactile cues to certain aspects of speech. Sth. Speech J., 24, 84-90 (1958).

McFARLANE, S. C., Neura1 response time of stutterers and nonstutterers for certain oral motor tasks as a function of auditory stimulation. Doctoral dissertation, Univ. of Washington (1975).

MacNEILAGE, P. F., Motor control of serial ordering of speech. Psycho1. Rev., 77, 182-196 (1970).

., KRONES, R., and HANSON, R., Closed-loop control of the initiation of jaw movement for speech. J. Acoust. Soc. Amer., 47, 104 (1970).

MADISON, C. L., and FUCCI, D. J., Speech-sound discrimination and tactile-kinesthetic discrimination in reference to speech production. Percep. and Mot. Ski11s, 33, 831-838 (1971).

MYSAK, E. D., Servotheory and stuttering. J. Speech Hearing Dis., 25, 188-195 (1960). ., Pathologies of Speech Systems. Baltimore, Md.: Williams and Wilkins (1976).

NESBITT, J., Lingual discrimination. Master's thesis, Portland State Univ. (1974).

OHMAN, S. E. G., Durations of formant frequency transitions. Stockholm, Sweden: Roya1 Institute of Technology, STL-QPSR, 10-13 $(1 / 1965)$.

PENDERGAST, K., DICKEY, S. E., SELMAR, J. W., and SODER, A. L., Photo Articulation Test. Danville, I11.: Interstate Printers \& Pub1ishers, Inc. (1969).

PENFIELD, W., and ROBERTS, L., Speech and Brain-Mechanisms. Princeton, N. J.: Princeton Univ. Press (1959).

PERKINS, W., RUDAS, J., JOHNSON, L., and BELL, J., Stuttering: Discoordination with articulation and respiration. J. Speech Hearing Res., 19, 509-522 (1976).

PROSEK, R. A., and HOUSE, A. S., Intra-oral air pressure as a feedback cue in consonant production. J. Speech Hearing Res., 18, 133-147 (1975). 
PUTNAM, A. H. B., and RINGEL, R. L., Some observations of articulation during labial sensory deprivation. J. Speech Hearing Res., 15, 529-542 (1972).

., A cineradiographic study of articulation in two talkers with temporarily induced oral sensory deprivation. J. Speech Hearing Res., 19, 241-246. (1976).

RINGEL, R. L., BURK, K. W., and SCOTT, C. M., Tactile perception: Form discrimination in the mouth. Brit. J. Dis. Comm., 3, 150-155 (1968).

RINGEL, R. L., and STEER, M. D., Some effects of tactile and auditory alterations on speech output. J. Speech Hearing Res., 6, 369378 (1963).

SALOMON, G., and STARR, A., Electromyography of middle-ear muscles in man during motor activities. Acta Neurol. Scand., 39, 161-168 (1963).

SCHLIESSER, H. F., and COLEMAN, R. O., Effectiveness of certain procedures for alteration of auditory and oral tactile sensation for speech. Percep. and Mot. Skills, 26, 275 (1968).

SCHWARTZ, M., The core of the stuttering block. J. Speech Hearing Dis., $39,169-177$ (1974).

SCOTT, C. M., and RINGEL, R. L., Articulation without oral sensory control. J. Speech Hearing Res., 14, 804-818 (1971).

SHAMES, G. H., and SHERRICK, C. E., A discussion of nonfluency and stuttering as operant behavior. J. Speech Hearing Dis., 28, 3-18 (1963).

SHEARER, W. M., Speech: Behavior of middle-ear muscles during stuttering. Science, 152, 1280 (1966).

., and SIMMONS, F. B., Middle-ear activity during speech in normal speakers and stutterers. J. Speech Hearing Res., 8, 203207 (1965).

SHEEHAN, J., Conflict theory of stuttering. In J. Eisenson (Ed.), Stuttering: A Symposium. New York: Harper and Row (1958).

STARKWEATHER, C. W., HIRSCHMAN, P., and TANNENBAUM, R. S., Latency of vocalization onset: Stutterers versus nonstutterers. J. Speech Hearing Res., 19, 481-492 (1976).

SUSSMAN, H. M., MacNEILAGE, P. F., and HANSON, R. J., Labial and mandibular dynamics during the production of bilabial consonants: Preliminary observations. J. Speech Hearing Res., 16, 397-420 (1973). 
TIKOFSKY, R. S., A revised 1ist for the estimation of dysarthric single word intelligibility. J. Speech Hearing Res., 13, 59-64 (1970).

TRAVIS, L. E., Speech Pathology. New York: Appleton (1931).

TROTTER, W. D., and LESCH, M. M., Personal experiences with a stutteraid. J. Speech Hearing Dis., 32, 270-272 (1967).

VAN RIPER, C., Speech Correction: Principles and Method. Englewood Cliffs, N. J.: Prentice-Ha11 (1954). ., The Nature of Stuttering. Englewood Cliffs, N. J.: PrenticeHa11 (1971).

., and IRWIN, J. V., Voice and Articulation. Englewood Cliffs, N. J.: Prentice-Ha11 (1958).

WEBSTER, R. L., A behavioral analysis of stuttering: Treatment and theory. In K. S. Calhoun, H. E. Adams, and K. M. Mitche11 (Eds.), Innovative Treatment Methods in Psychopathology, Wiley and Sons, Inc. (1974).

., Voice onset delay in stutterers with masking to a visual cue. Personal communication (1977).

., and LUBKER, B. B., Interrelationships among fluency producing variables in stuttered speech. J. Speech Hearing Res., 11, 754760 (1968).

WEST, R., Is stuttering abnormal? J. Abnorm. Psycho1, , 31, 76-86 (1936).

WISCHNER, G. J., Stuttering behavior and learning: A preliminary theoretical formulation. J. Speech Hearing Dis., 15, 324-335 (1950).

YATES, A. J., Delayed auditory feedback and shadowing. Quart. J. Exp. Psychol.., 17, 125-131 (1965). 
APPENDIX A

INFORMED CONSENT

I, hereby agree to serve as a subject in the research project on the effects of oral sensory deprivation upon articulatory behavior of stutterers vs. nonstutterers conducted by Clifford S. Goldman, M.A., Speech-Language Pathologist. I understand that the study involves receiving bilateral mandibular nerve block injections and a nerve block injection in the area of the incisive forament of the anterior hard palate from a licensed dentist.' I understand that the possible risks to me associated with this study are: nerve damage with parasthesia, days to months in duration; hematoma with vessel damage, pain and/or fear reaction; I.V. injection causing a change in heart rate and/or pressure. I also am aware that these are the same risks encountered by a patient receiving routine dental care.

I am aware of the following safeguards:

Dental safeguards include the observance of standard dental procedures: (1) the adherence to strict instrumentation sanitation using laminated rather than one piece needles to insure against infection and needle breaking respectively, and (2) use of aspirating syringes, injected slowly with intermittent aspirations.

It has been explained to me that the purpose of the study is to learn more about the factors related to the cause of stuttering. I may not receive any direct benefit from participating in this study, but my participation may help to increase knowledge which may benefit others in the future.

Mr. Goldman has offered to answer any questions I may have about the study and what is expected of me. I understand that I am free to withdraw from participation in this study at any time without jeopardizing my relationship with Portland State University.

I have read the foregoing information.

Date Signed 
APPENDIX B

DENTIST AUTHORIZATION

Dear Dr. Nakata,

The experimental condition which I discussed with you by phone will be imposed upon the subjects by Dr. Alan Clarke, D.M.D. A bilateral mandibular nerve block and a nerve block in the area of the incisive foramen of the anterior hard palate will be administered employing carbocaine. A topical anesthetic will be applied to the entire surface of the hard palate.

We are testing to see if stutterers' articulation proficiency is less affected than normally fluent subjects while in a state of oral sensory deprivation: It has been hypothesized that stutterers monitor their speech primarily auditorily and that nonstutterers monitor speech production chiefly via oral sensory feedback.

The results of this study may contribute toward a further understanding of the etiology of stuttering.

Thank you for your cooperation. Please sign below and return to me.

(Sgd.) C1ifford S. Goldman

Clifford S. Goldman, M.A. Speech Pathologist

My patient has not exhibited idiosyncratic reactions to oral anesthetization procedures while under my dental care, and as far as $I$ know he does not have such a history.

(Sgd.) R. K. Nakata, D.M.D. 


\section{APPENDIX C}

\section{INSTRUCTIONS TO JUDGES}

\section{Evaluating Articulatory Proficiency of Speakers in a State of Oral Sensory Deprivation}

You are about to listen to individuals reading the Tikofsky intelligibility word list. Each tape contains the production of fifty words uttered at the rate of about one every five seconds. Not all the words have been articulated correctly, as all the subjects produced them while being in a state of oral sensory deprivation.

Listen to each word and score it as being correct or incorrect. If the word is produced correctly, mark it plus $(+)$ on the score sheet provided. If it is articulated incorrectly identify the error as being one of omission, substitution, addition or distortion in the column labeled Identification. If a sound is added write that sound followed by the target sound. If the sound is omitted record a minus sign (-), slash, then the target sound. If the sound is substituted, write the phonetic symbol of the substitution, slash, target sound. If the sound is distorted, record severity as D1 (mild), D2 (moderate), or D3 (severe), slash, followed by the target sound.

If you would like, any one word will be repeated once. Remember you have about five seconds to make your judgment after you have heard the word before the next word will be heard. There will be a one minute delay between tapes. 
APPENDIX D

JUDGES!' RESPONSE SHEET

Subject

Word

+ or -

Identification of Error

Barb

Tongue

Duckpond

Spice

Showered

Shank

Sleeps

Sketch

Charge

Man

Daybreak

Platform

Scarecrow

Drawbridge

Playground

Crown

Northwest

Lifeboat

Scrub 
APPENDIX D (Cont.)

Word

+ or -

Identification of Error

Blush

Starlight

Sledge

Earthquake

Buckwheat

Wildcat

With

Champ

Thread

Woodwork

More

Bind

Train

Mushroom

Dwarf

Ink We11

Washboard

Fused

Cookbook

Joke

Schoolboy

Shrug

Bounce

Sheep 
APPENDIX D (Cont.)

Word

+ or - Identification of Error

Eggplant

Twist

Shipwreck

Grove

Bush

Chant

Cute 
APPENDIX: E

ANESTHETIZATION CRITERIA SCORING SHEET

Subject

Date

1. $\overbrace{3}^{\text {Form }} \quad$ Pre Post $\quad$ Post

2. (O)

3. $\square$

4. 5

5. $\Delta$

6. M

7. $\square$

8.

9. $\square$

10. 
APPENDIX F

SUMMARY OF JUDGES' SCORING CORRECT AND MISARTICULATED RESPONSES OF BOTH SAMPLES

\section{Stutterers}

Word Subj. 3 Subj. 4 Subj. 6 Subj. 8 Subj. 9 Subj. 10

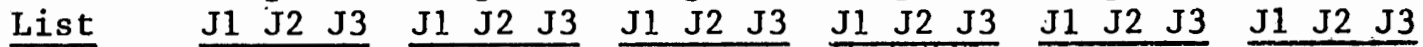

Barb

Tongue

Duckpond

Spice

Showered

Shank

Sleeps

Sketch

Charge

Man

Daybreak

Platform

Scarecrow

Drawbridge

P1ayground

Crown

Northwest

Lifeboat 
APPENDIX F (Cont.)

Word Subj. 3 Subj. 4 Subj. 6 Subj. 8 Subj. 9 Subj. 10

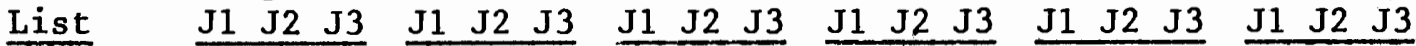

Scrub

Blush

Starlight

sledge

Earthquake

Buckwheat

Wildcat

With

Champ

Thread

Woodwork

More

Bind

Train

Mushroom

Dwarf

Ink we11

Washboard

Fused

Cookbook

Joke

Schoolboy

Shrug

Bounce 
APPENDIX F (Cont.)

Word Subj. 3 Subj. 4 Subj. 6 Subj. 8 Subj. 9 Subj. 10

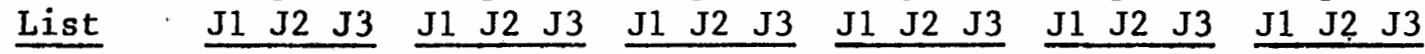

Sheep

Eggplant

Twist

Shipwreck

Grove

Bush

Chant

Cute

\section{Nonstutterers}

Word Subj. 1 Subj. 2 Subj. 5 Subj. $7 \quad$ Subj. 11 Subj. 12

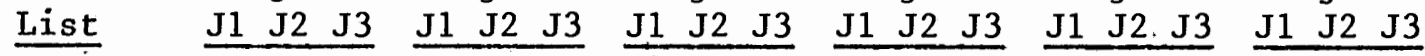

Barb

Tongue

Duckpond.

Spice

Showered

Shank

sleeps

Sketch

Charge

Man

Daybreak

Platform 


\section{APPENDIX F (Cont.)}

Word Subj. 1 Subj. 2 Subj. 5 Subj. 7 Subj. 11 Subj. 12

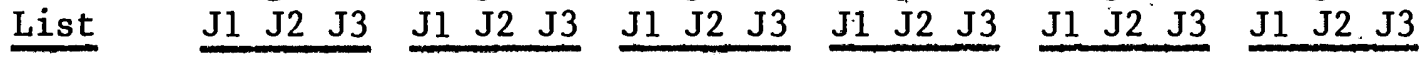

Scarecrow $--\infty++++++++$ Drawbridge $-\quad-\quad-\quad-++++++-$ Playground $-\quad-+++++++++++$ Crown

Northwest

Lifeboat

Scrub

Blush

Starlight

sledge

Earthquake

Buckwheat

Wildcat

With

Champ

Thread

Woodwork

More

Bind

Train

Mushroom

Dwarf

Ink we11 


\section{APPENDIX F (Cont.)}

Word Subj. $1 \quad$ Subj. 2 Subj. 5 Subj. $7 \quad$ Subj. 11 Subj. 12

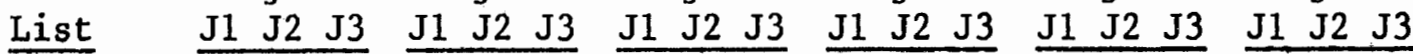

Washboard

Fused

Cookbook

Joke

Schoolboy

Shrug

Bounce

Sheep

Eggplant

Twist

Shipwreck

Grove

Bush

Chant

Cute 